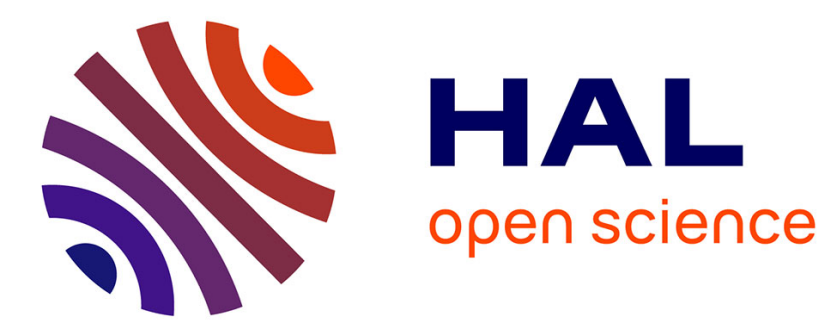

\title{
Seasonal Flutuations and Equilibrium Models of Exchange Rate
}

Juan-Angel Jimenez-Martin, Rafael Flores-Defrutos

\section{To cite this version:}

Juan-Angel Jimenez-Martin, Rafael Flores-Defrutos. Seasonal Flutuations and Equilibrium Models of Exchange Rate. Applied Economics, 2009, 41 (20), pp.2635-2652. 10.1080/00036840701222603 . hal-00582140

\section{HAL Id: hal-00582140 \\ https://hal.science/hal-00582140}

Submitted on 1 Apr 2011

HAL is a multi-disciplinary open access archive for the deposit and dissemination of scientific research documents, whether they are published or not. The documents may come from teaching and research institutions in France or abroad, or from public or private research centers.
L'archive ouverte pluridisciplinaire HAL, est destinée au dépôt et à la diffusion de documents scientifiques de niveau recherche, publiés ou non, émanant des établissements d'enseignement et de recherche français ou étrangers, des laboratoires publics ou privés. 


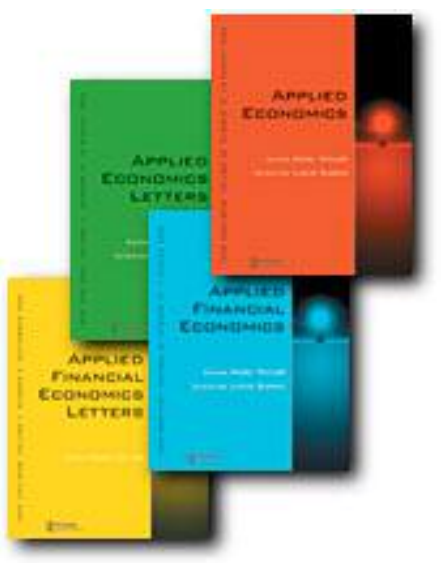

Seasonal Flutuations and Equilibrium Models of Exchange Rate

\begin{tabular}{|r|l|}
\hline Journal: & Applied Economics \\
\hline Manuscript ID: & APE-06-0353.R1 \\
\hline Journal Selection: & Applied Economics \\
\hline Date Submitted by the & $15-J a n-2007$ \\
\hline Author: & \begin{tabular}{rl|} 
Complete List of Authors: \\
Jimenez-Martin, Juan-Angel; UNIVERSIDAD COMPLUTENSE DE \\
MADRID, FDMTOS. ANALISIS ECONOMICO II \\
Flores-DeFrutos, Rafael; Universidad Complutense de Madrid, \\
Análisis Económico II
\end{tabular} \\
\hline JEL Code: & $\begin{array}{l}\text { F31 - Foreign Exchange < F3 - International Finance < F - } \\
\text { and Simulation < F3 - International Finance < F - International } \\
\text { Economics, G15 - International Financial Markets < G1 - General } \\
\text { Financial Markets < G - Financial Economics }\end{array}$ \\
\hline Keywords: & \begin{tabular}{l} 
Exchange rate, Equilibrium model, Seasonality \\
\hline
\end{tabular} \\
\hline
\end{tabular}

\section{S ScholaroNE \\ Manuscript Central}




\title{
SEASONAL FLUCTUATIONS AND EQUILIBRIUM MODELS OF EXCHANGE RATE
}

\author{
Juan Ángel Jiménez Martín ${ }^{\text {a }}$ \\ Rafael Flores de Frutos ${ }^{\mathrm{b}}$ \\ ${ }^{\text {a }}$ Dpto. de Fundamentos de Análisis Económico II, Universidad Complutense. \\ ${ }^{\mathrm{b}}$ Dpto. de Fundamentos de Análisis Económico II, Universidad Complutense.
}

\begin{abstract}
Most of the evidence on dynamic equilibrium exchange rate models is based on seasonally adjusted consumption data. Equilibrium models have not worked well in explaining the actual exchange rate, but with seasonally adjusted data, there are reasons to expect spurious rejections of the model. This paper models exchange rate dynamics by means of an equilibrium model that incorporates seasonal preferences. The fit of the model to the data is evaluated for five industrialized countries using seasonally unadjusted data. Our findings indicate that a model with seasonal preferences can generate monthly time series of the exchange rate without seasonality, even if the variables that theoretically determine the exchange rate show seasonality. We also compare the stochastic properties of the theoretical exchange rate and observed exchange rate using cointegration analysis, finding cointegration between both time series in some cases.
\end{abstract}

JEL classification: F31, F37, G15

Keywords: exchange rate, equilibrium model, seasonality.

\footnotetext{
${ }^{*}$ Corresponding author. Dpto. de Fundamentos de Análisis Económico II, Universidad Complutense, Somosaguas, 28223, Spain. Tel.: +34 9139423 55. Fax: +34 91394 2613. E-mail: juanangel@ccee.ucm.es
} 


\title{
SEASONAL FLUCTUATIONS AND EQUILIBRIUM MODELS OF EXCHANGE RATE
}

\begin{abstract}
Most of the evidence on dynamic equilibrium exchange rate models is based on seasonally adjusted consumption data. Equilibrium models have not worked well in explaining the actual exchange rate, but with seasonally adjusted data, there are reasons to expect spurious rejections of the model. This paper models exchange rate dynamics by means of an equilibrium model that incorporates seasonal preferences. The fit of the model to the data is evaluated for five industrialized countries using seasonally unadjusted data. Our findings indicate that a model with seasonal preferences can generate monthly time series of the exchange rate without seasonality, even if the variables that theoretically determine the exchange rate show seasonality. We also compare the stochastic properties of the theoretical exchange rate and observed exchange rate using cointegration analysis, finding cointegration between both time series in some cases.
\end{abstract}

JEL classification: F31, F37, G15

Keywords: exchange rate, equilibrium model, seasonality. 


\section{1.- Introduction}

Most of the evidence on dynamic equilibrium exchange rate models is based on seasonally adjusted consumption data. Equilibrium models state that the exchange rate is determined by macroeconomic fundamentals such as money supplies, prices, outputs, and interest rates. To our current knowledge, no previous studies have explored the idea of developing a equilibrium model of exchange rate consistent with the data: seasonality is inherent in the fundamental variables determining the theoretical exchange rate, but seasonality does not appear in the exchange rate.

Econometricians, rather than explicitly investigating the underlying economic seasonal variation, typically remove its effects by using seasonally adjusted data. Wallis (1974) shows that seasonal adjustment may distort the relations between variables. The effect of seasonal adjustmet on asset pricing evidence has received only limited attention in the literature. Miron (1986) extended the seminal work of Hansen and Singleton (1982) to incorporate seasonal "taste shocks". Miron (1986) shows that when the seasonal fluctuations in consumption purchases are included in an analysis of the life cycle-permanent income model, there is no evidence in the aggregate data against the model. Ferson and Harvey (1992) examined consumption-based asset pricing models using seasonally unadjusted consumption data. They generalize the model of seasonality proposed by Miron (1986) studying models with "subsistence levels" in which the seasonal parameters are related to expected risk premium. They find that a model using not seasonally adjusted consumption data and nonseparable preferences with seasonal effects works better according to several criteria.

This paper generalizes standard dynamic equilibrium models of exchange rates by allowing for seasonal shocks in preferences. In contrast with prior studies, the theoretical model is tested directly with seasonal unadjusted data. We present a twocountry open economy model that is a variation of the one developed in Grilli and Roubini (1992). Our model incorporates preferences with "taste shocks", as in Miron (1986). In Miron's model there are seasonal "shocks" to preferences indicating that the utility obtained from the consumption varies according to the prevailing season. In our 
model, this kind of preferences allows the agents to smooth the seasonality in the fundamental variables.

When seasonal preferences are considered, we find that the theoretical exchange rate is a function not only of the share of money used for asset transaction, goods endowments and the return on equities, as in previous equilibrium models, but also of seasonal shifts in preferences. The rationale underlying this is that consumers know that fundamental variables present seasonal variations, but their welfare improves if they smooth them over the entire year, thus avoiding the creation of intertemporal distortions when making their decision to invest. This may explain an exchange rate without seasonality.

We subsequently evaluate the fit of our model to the data in four steps: (i) we obtain the GMM estimation of the structural parameters of the model using seasonally unadjusted data; (ii) we generate theoretical monthly time series of the exchange rate using the model equilibrium conditions evaluated at the point estimates of structural parameters using the corresponding money, production and asset returns observed; (iii) we analyze stochastic properties of theoretical exchange rates using Box-Jenkins methodology; and finally, (iv) we compare the stochastic properties of the theoretical and observed exchange rate using cointegration analysis.

The results indicate that our model, which considers preferences with seasonal effects, explains how agents smooth seasonal movements in fundamental variables when they make their decisions to invest. Even if seasonality appears in the variables that theoretically explain the exchange rate, our model could generate time series for some exchange rates with similar properties to the actual rate, i.e. (i) no seasonal fluctuations, and (ii) a degree of integration equal to 1. Furthermore, the same order of integration between actual and simulated exchange rate time series leads to the study of cointegration. This property has been found in some cases, but the cointegration vector only presented the right sign (i.e. the model replicates the observed depreciation of the British pound) for the British pound / US dollar exchange rate.

The paper is organized as follows. Section 2 presents a two-country, two-goods cash-in-advance (CIA) model of the exchange rate; in this section we describe a specific utility function with seasonal shocks. We evaluate our model in Section 3. To begin 
with, the parameters are estimated applying the GMM estimator over stochastic Euler equations, we then generate time series of the theoretical exchange rate for several currencies and finally compare the stochastic properties of the theoretical and observed exchange rate. Concluding remarks appear in Section 4. Appendix 1 contains a description of the data. Appendix 2 shows the diagnostic analysis of GMM estimation. Appendix 3 presents time series data of observed and theoretical exchange rates.

\section{2.- The economy}

This section presents a CIA two-country economy that is subject to seasonal variation in preferences. A predecessor of this model is the work of Grilli and Roubini (1992), which analyzed the open economy implications of models in which money is used both for transactions on goods markets and for transactions on asset markets. In this paper, however, in contrast to Grilli and Roubini, securities are traded instead of bonds and preferences with seasonal shocks are specified. First, we describe the economy and analyze the main implications of our model specifications for the equilibrium exchange rate. We then present the preferences, which are particularly important for the outcome of our analysis. Finally, the theoretical equilibrium exchange rate is obtained as an explicit function of fundamental variables and preference parameters.

\section{A.- The two-country exchange rate model}

There are two countries: Domestic (D) and Foreign (F). Each country has a firm, each produces a perishable, traded, distinct good: $Y_{t}^{D}, Y_{t}^{F}$. Firms are assumed to be able to sell claims of their future random outputs. Domestic (foreign) claims entitle the owner to a proportionate share in the future stream of dividends.

There is one representative agent in each country. The representative agent from countries $i$, for $i=D, F$, has preferences described by an infinite-horizon expected utility function given by: 


$$
E_{t}\left[\sum_{s=t}^{\infty} \beta^{s-t} U\left(c_{i s}^{D}, c_{i s}^{F}\right)\right] \quad 0<\beta<1,
$$

where $E_{t}$ denotes the mathematical conditional expectation on information known at the beginning of period $t, \beta$ is a constant discount factor. Function $U$ is assumed to be bounded, continuously differentiable, increasing in both arguments, and strictly concave. $c_{i s}^{j}$, for $j=D, F$, is the good produced in country $j$ that is consumed by a resident of country $i$. Note that preferences are assumed to be identical across countries.

Residents of country $i$ are allowed to own shares in production in either country as well as the currency. The pattern of trading is assumed to proceed in a similar way to Lucas (1990). ${ }^{1}$ The transaction technology is that of the cash-in-advance model, extended by the assumption that the representative agent faces two liquidity constraints: one on the purchase of goods and one on the purchase of assets. Domestic (foreign) goods may be bought only with domestic (foreign) currency. Agents are thus subject to the following cash-in-advance constraints. Let $N_{i t}^{j}$ be the amount of money of country $j$ held by the representative agent of country $i$ for transactions in the goods market at time $t$, and let $P_{t}^{j}$ be the domestic and foreign currency prices for good $j$. Then we require:

$$
\begin{aligned}
& N_{i t}^{D} \geq P_{t}^{D} c_{i t}^{D}, \quad i=D, F, \\
& N_{i t}^{F} \geq P_{t}^{F} c_{i t}^{F}, \quad i=D, F,
\end{aligned}
$$

Constraint (2) pertains to the currency of the domestic country, whereas (3) pertains to the currency of the foreign country. We now analyze equilibrium price

${ }^{1}$ We assume the convenient artifact of a three-member representative household, each of whom goes his own way during a period, the three regrouping at the end of a day to pool goods, assets, and information. One member of the household (the owner of the firm) collects the production, which he must then sell to other households on a cash-in-advance basis. A household cannot consume any of its own endowments. Cash received from a sale on date- $t$ cannot be used for any purpose during period $t$. A second member of the household takes an amount $M_{t}-Z_{t}$ of the household's initial cash balances $\left(M_{t}\right)$ and uses it to purchase goods from other households. The stock agents start out with the money that was paid to them as dividends by domestic and foreign firms during this period. The third member carries out the remaining domestic and foreign currency cash balances on the securities market where domestic and foreign securities are sold and bought, and where he can buy and sell domestic and foreign currencies on the foreign exchange market. In addition, domestic (foreign) assets can be bought only with domestic (foreign) cash balances. Only two securities are assumed to exist in the securities market: domestic and foreign equity claims (shares in domestic and foreign future outputs). 
determination. Equilibrium conditions for the currency for transactions on the goods markets are:

$$
N_{t}^{j}=N_{D t}^{j}+N_{F t}^{j}, \quad j=D, F
$$

Substituting (2)-(3) at equality in (4) gives:

$$
N_{t}^{j}=P_{t}^{j}\left(c_{D t}^{j}+c_{F t}^{j}\right), \quad j=D, F .
$$

Equilibrium in the goods markets requires:

$$
Y_{t}^{j}=c_{D t}^{j}+c_{F t}^{j}, \quad j=D, F .
$$

Substituting (6) in (5) gives the quantitative theory equations:

$$
\begin{aligned}
& P_{t}^{D}=N_{t}^{D} / Y_{t}^{D} \\
& P_{t}^{F}=N_{t}^{F} / Y_{t}^{F}
\end{aligned}
$$

Therefore, the equilibrium prices of the two goods depend on domestic and foreign money supply.

In addition, there are two types of equities in this economy: domestic and foreign. These equities are traded on the securities market at a price (in units of domestic (foreign) currency) $Q^{D}{ }_{t}\left(Q^{F}{ }_{t}\right)$. During the securities trading session, the agent has access to the foreign exchange market and can choose holdings of domestic and foreign securities. He therefore faces the budget constraints given by:

$$
\left[M_{i t}^{D}-N_{i t}^{D}\right]+S_{t}\left[M_{i t}^{F}-N_{i t}^{F}\right]=Q_{t}^{D} \omega_{i t}^{D}+S_{t} Q_{t}^{F} \omega_{i t}^{F}, \quad i=D, F,
$$

where $S_{t}$ is the nominal spot exchange rates expressed as the domestic price for foreign currency, $M_{i t}^{j}$ are $i$ holdings of money $j$ on date $t$, and $\omega_{i t}^{j}$ is the number of equities of country $j$ purchased at $t$ by a resident of country $i$.

In each period, the firm from country $j$ issues an amount of equities, the value of which has to be equal to its production. Thus:

$$
P_{t}^{j} Y_{t}^{j}=\left(\omega_{D, t}^{j}+\omega_{F, t}^{j}\right) Q_{t}^{j} \quad j=\mathrm{D}, \mathrm{F},
$$

At the beginning of period $t+1$, the ownership of equities entitles the owner to receive the dividend and to have the right to sell the equity at price $Q_{t+l}^{i}$. Dividends are random because they depend on production, which is assumed to be governed by an 
unspecified stochastic process $^{2}$. Therefore, the agent will begin $t+1$ with cash balances given by

$$
\begin{array}{ll}
M_{i t+1}^{D}=d_{t+1}^{D} \omega_{i t}^{D}+Q_{t+1}^{D} \omega_{i t}^{D} & i=D, F \\
M_{i t+1}^{F}=d_{t+1}^{F} \omega_{i t}^{F}+Q_{t+1}^{F} \omega_{i t}^{F} & i=D, F,
\end{array}
$$

where $\mathrm{d}_{\mathrm{t}}^{\mathrm{j}}$ are dividends per equity of firm $j(j=\mathrm{D}, \mathrm{F})$.

The domestic agent's optimization problem may now be represented as follows. The agent chooses stochastic processes for $\left\{\mathrm{N}^{\mathrm{D}}{ }_{\mathrm{Dt}}, \mathrm{N}^{\mathrm{F}} \mathrm{Dt}, \omega^{\mathrm{D}}{ }_{\mathrm{Dt}}, \omega^{\mathrm{F}}{ }_{\mathrm{Dt}}\right\}^{\propto}{ }_{\mathrm{t}=0}$ to maximize (1) subject to the cash-in-advance constraints (2)-(3), the budget constraint (8) and the transition equation for state variables (10)-(11). The agent's decision problem motivates Bellman's equation,

$$
\mathrm{V}\left(\mathrm{M}_{\mathrm{Dt}}^{\mathrm{D}}, \mathrm{M}_{\mathrm{Dt}}^{\mathrm{F}}\right)=\operatorname{Max} \mathrm{U}\left(\mathrm{N}_{D t}^{D} / \mathrm{P}_{t}^{D}, \mathrm{~N}_{D t}^{F} / \mathrm{P}_{t}^{F}\right)+\beta \mathrm{E}_{\mathrm{t}}\left\{\mathrm{V}\left(\mathrm{M}_{\mathrm{Dt}+1}^{\mathrm{D}}, \mathrm{M}_{\mathrm{Dt}+1}^{\mathrm{F}}\right)\right\}
$$

First order and envelope conditions associated with the problem stated in (12) are used to characterize equilibrium behavior, assuming that the value functions exist and that they are increasing, differentiable and concave:

$$
\begin{gathered}
\partial V / \partial \mathrm{N}_{\mathrm{Dt}}^{\mathrm{D}}=U_{c_{D}^{D}}\left(c_{D t}^{D}, c_{D t}^{F}\right)\left(P_{t}^{D}\right)^{-1}=\lambda_{\mathrm{t}} \\
\partial V / \partial \mathrm{N}_{\mathrm{Dt}}^{F}=U_{c_{D}^{F}}\left(c_{D t}^{D}, c_{D t}^{F}\right)\left(P_{t}^{F}\right)^{-1}=\lambda_{\mathrm{t}} \mathrm{S}_{\mathrm{t}} \\
\partial \mathrm{V} / \partial \omega_{\mathrm{Dt}}^{\mathrm{D}}=\mathrm{Q}_{\mathrm{t}}^{\mathrm{D}} \lambda_{\mathrm{t}}=\beta \mathrm{E}_{t}\left[\mathrm{~V}_{\mathrm{M}_{D t+1}^{D}}^{\prime}\left(d_{\mathrm{t}+1}^{\mathrm{D}}+\mathrm{Q}_{\mathrm{t}+1}^{\mathrm{D}}\right)\right], \\
\partial \mathrm{V} / \partial \omega_{\mathrm{Dt}}^{F}=\mathrm{Q}_{\mathrm{t}}^{\mathrm{F}} \lambda_{\mathrm{t}} \mathrm{S}_{\mathrm{t}}=\beta \mathrm{E}_{t}\left[\mathrm{~V}_{\mathrm{M}_{\mathrm{Dt}+1}^{F}}\left(\mathrm{~d}_{\mathrm{t}+1}^{\mathrm{F}}+\mathrm{Q}_{\mathrm{t}+1}^{\mathrm{F}}\right)\right],
\end{gathered}
$$

where $\lambda_{t}$ is the multiplier associated with the budget constraint.

The envelope conditions are:

$$
\begin{aligned}
& \mathrm{V}_{\mathrm{M}_{\mathrm{D}++1}^{\mathrm{D}}}^{\prime}=U_{c_{D}^{D}}\left(c_{D t+1}^{D}, c_{D t+1}^{F}\right)\left(P_{t+1}^{D}\right)^{-1} \\
& \mathrm{~V}_{\mathrm{M}_{\mathrm{D} t+1}^{F}}^{\prime}=U_{c_{D}^{F}}\left(c_{D t+1}^{D}, c_{D t+1}^{F}\right)\left(P_{t+1}^{F}\right)^{-1}
\end{aligned}
$$

Substituting (13) and (17) in (15), the domestic firm equity price is given by:

${ }^{2}$ Note that our ultimate goal is the simulation of exchange rate time series. The simulation methodology does not involve positing a statistical model for the exogenous variables. 


$$
Q_{t}^{D}=\beta E_{t}\left(\frac{U_{c_{D}^{D}}\left(c_{D t+1}^{D}, c_{D t+1}^{F}\right)\left(P_{t+1}^{D}\right)^{-1}}{U_{c_{D}^{D}}\left(c_{D t}^{D}, c_{D t}^{F}\right)\left(P_{t}^{D}\right)^{-1}}\left(d_{t+1}^{D}+Q_{t+1}^{D}\right)\right)
$$

Symmetrically, substituting (14) and (18) in (16), the foreign firm equity price is given by:

$$
Q_{t}^{F}=\beta E_{t}\left(\frac{U_{c_{D}^{F}}\left(c_{D t+1}^{D}, c_{D t+1}^{F}\right)\left(P_{t+1}^{F}\right)^{-1}}{U_{c_{D}^{F}}\left(c_{D t}^{D}, c_{D t}^{F}\right)\left(P_{t}^{F}\right)^{-1}}\left(d_{t+1}^{F}+Q_{t+1}^{F}\right)\right)
$$

Finally, the solution for the equilibrium exchange rate is obtained from first order conditions (15)-(16), and envelope conditions (17)-(18):

$$
S_{t}=\frac{E_{t}\left[U_{c_{D}^{F}}\left(c_{D t+1}^{D}, c_{D t+1}^{F}\right)\left(P_{t+1}^{F}\right)^{-1}\left(d_{t+1}^{F}+Q_{t+1}^{F}\right)\left(Q_{t}^{F}\right)^{-1}\right]}{E_{t}\left[U_{c_{D}^{D}}\left(c_{D t+1}^{D}, c_{D t+1}^{F}\right)\left(P_{t+1}^{D}\right)^{-1}\left(d_{t+1}^{D}+Q_{t+1}^{D}\right)\left(Q_{t}^{D}\right)^{-1}\right]}
$$

If we compare (21) with the expression for the exchange rate in a typical cashin-advance model, we notice that the crucial difference is represented by the ratio of returns from the investment on domestic and foreign equities. The intuition for the effect of this ratio on the equilibrium exchange rate is clear: part of the money supply is held for use in the asset market and thus does not enter in the determination of the goods prices. In particular, since goods prices depend on the money used in goods transactions, an increase in the returns expected from the investment on foreign equities, will increase the foreign money held for asset transaction, dropping the foreign money available for good market transactions. Consequently, this tends to reduce the foreign equilibrium prices of goods and thus depreciate the exchange rate.

To generate time series of theoretical exchange rate, it is necessary to characterize the agent preferences; in the next section, we present our assumption on these preferences.

\section{B- Seasonal shifts in preferences}


The issue of interest is that although the exchange rate is not seasonal, seasonal movements are a feature of many economic data series that theoretically determine the exchange rate, such as Gross Domestic Product (GDP), Industrial Product (IP), consumption, monetary aggregates, etc. The evidence suggests that optimizing agents know that fundamental variables present seasonal variations and they smooth these when making an investment decision.

The question is: How can our equilibrium model explain this fact? In our model, expression (21) describing the solution for the equilibrium exchange rate can be written as:

$$
\mathrm{S}_{\mathrm{t}}=\frac{E_{t}\left(m_{t+1}^{F} R_{t+1}^{F}\right)}{E_{t}\left(m_{t+1}^{D} R_{t+1}^{D}\right)}
$$

where $m_{t+1}^{j}=U_{c_{D}^{j}}\left(c_{D t+1}^{D}, c_{D t+1}^{F}\right)\left(P_{t+1}^{j}\right)^{-1}$, for $j=D, F$, is the marginal utility gained from $\left(P_{t+1}^{j}\right)^{-1}$ units of commodity $c_{D t+1}^{j}$ consumed at $t+1$, and $R_{t+1}^{j}=\left(\mathrm{d}_{\mathrm{t}+1}^{j}+\mathrm{Q}_{\mathrm{t}+1}^{j}\right)\left(Q_{\mathrm{t}}^{j}\right)^{-1}$ is the return on shares of country $j .{ }^{3}$ Therefore, the equilibrium exchange rate equalize marginal utilities of currency across countries, when evaluated in a common currency. ${ }^{4}$

Since the exchange rate is not seasonal, we should not observe any seasonal variation on the marginal utility of the expected returns from the investment on shares. Note that $m_{t+1}$ is a function of consumption, and consumption usually possesses seasonality. Therefore, the seasonal pattern in consumption should be reflected in $R_{t+1}^{j}$ (however, the seasonal variation on asset returns, $R_{t+1}^{j}$ is minute compared with seasonal fluctuations in consumption) unless the agents remove seasonal fluctuations in

\footnotetext{
${ }^{3}$ The amount of commodity $c^{j}{ }_{D t+1}$ that can be purchased with a unit of $j$ currency at time $t+1$ is the inverse
} of its price $\left(P^{j}{ }_{t+1}\right)^{-1}$. The utility from each one of these units of $c_{D t^{+}+}^{j}$ is given by its marginal utility, $U_{c_{D}^{j}}\left(c_{D t+1}^{D}, c_{D t+1}^{F}\right)$.

${ }^{4}$ For instance, for the UK pound / US dollar exchange rate case: the marginal utility expected from the investment of one pound on UK shares is $E_{t}\left(m^{D}{ }_{t+1} R^{D}{ }_{t+1}\right)$; the marginal utility expected from the investment of one pound on US shares is $E_{t}\left(m^{F}{ }_{t+1} R^{F}{ }_{t+1}\right) / S_{t}$, that is, the US dollar value of a pound $\left(1 / S_{t}\right)$ multiplied by the marginal utility expected from the investment on US shares. 
consumption (for example, through function $U_{c_{D}^{j}}$ ) to a level that can be exactly mirrored in the real returns of all assets.

In our model, we conjecture that preferences that include seasonal shocks may counteract the seasonality in the fundamental variables. Therefore, we assume that the representative agents from both countries have identical preferences described by Miron, $(1986)^{5}$ :

$$
U\left(c_{i t}^{D}(s), c_{i t}^{F}(s)\right)=\frac{1}{1-\gamma^{D}}\left(c_{i t}^{D}(s)\right)^{1-\gamma^{D}}+\frac{1}{1-\gamma^{F}}\left(c_{i t}^{F}(s)\right)^{1-\gamma^{F}},
$$

where $c_{i t}^{j}(s)$ is the consumption service flow received in period $t$ by the agent from country $i$ for the consumption of the good produced in country $j$, in season $s$, and $\gamma^{j}$ is the intertemporal elasticity of substitution in consumption of the consumption service of the good produced in country $j$. Consumers transform the stock of the consumption good produced in country $j, c_{i t}^{j}$, into consumption services according to the following function:

$$
\begin{aligned}
& c_{i t}^{j}(s)=\exp \left(\lambda^{j}{ }_{t}\right) c_{i t}^{j}, \quad j=D, F \\
& \lambda^{j}{ }_{t}=\theta_{1}^{\mathrm{j}} \mu_{t}(1)+\theta_{2}^{\mathrm{j}} \mu_{t}(2)+\ldots+\theta_{s}^{\mathrm{j}} \mu_{t}(s)
\end{aligned}
$$

where $\mu_{t}(s)$ is a dummy variable taking the value one when period $t$ corresponds to season $s$, and zero otherwise, and $\theta_{s}^{j}$ is the seasonal preference in season $s$. These parameters indicate that the utility obtained from $c_{i t}^{j}$ varies according to the prevailing season $s . c_{i t}^{j}(s)$ may thus be thought of as the "seasonally adjusted" consumption.

${ }^{5}$ We assume that the utility function is additively separable from the two consumption services and presents constant intertemporal substitution elasticity. Although this assumption is restrictive, it simplifies estimation considerably. Our analysis focuses on a simple basic utility function with seasonal shocks. We think this is valuable for setting a benchmark. Even so, the literature on equilibrium models of exchange rates includes heterogeneity of agents, multiple sectors, tax shocks, and modifications designed to reproduce features of exchange rates. Whether our findings are relevant for these cases is an open, quantitative issue that may be addressed using the procedures implemented in this paper. 


\section{C.- Characterizing the equilibrium exchange rate}

In order to describe an equilibrium solution of the model, we require a distribution of wealth. We have assumed that wealth of every kind is evenly divided between the residents of the two countries. Specifically, the residents of each country own half of the domestic and foreign endowments, the stocks of domestic and foreign money and domestic and foreign assets. Given this distribution of wealth, consumption is given by: ${ }^{6}$

$$
\begin{gathered}
c_{i t}^{D}=Y_{t}^{D} / 2, \quad i=D, F \\
c_{i t}^{F}=Y_{t}^{F} / 2, \quad i=D, F
\end{gathered}
$$

In addition, considering equilibrium prices given by (7) and the preferences defined above, (23)-(24), the equilibrium exchange rate given by expression (21) becomes:

$$
\mathrm{S}_{\mathrm{t}}=\frac{(1 / 2)^{-\gamma^{F}} E_{t}\left(\left(\exp \left[\sum_{\mathrm{s}=1}^{12} \theta_{S}^{F} \mu_{\mathrm{t}+1}(s)\right] \mathrm{Y}_{\mathrm{t}+1}^{\mathrm{F}}\right)^{1-\gamma^{F}}\left(\mathrm{~N}_{\mathrm{t}+1}^{\mathrm{F}}\right)^{-1} R_{t+1}^{F}\right)}{(1 / 2)^{-\gamma^{D}} E_{t}\left(\left(\exp \left[\sum_{\mathrm{s}=1}^{12} \theta_{S}^{D} \mu_{\mathrm{t}+1}(s)\right] \mathrm{Y}_{\mathrm{t}+1}^{D}\right)^{1-\gamma^{D}}\left(\mathrm{~N}_{\mathrm{t}+1}^{D}\right)^{-1} R_{t+1}^{D}\right)},
$$

${ }^{6}$ This solution is the perfectly pooled equilibrium of Lucas (1982). Cole and Obstfeld (1991) show that the efficient allocations of resources in an economy like the one considered in this paper is of the form:

$$
\begin{aligned}
& c_{D t}^{D}=\theta_{1} Y_{t}^{D} \Rightarrow c_{F t}^{D}=\left(1-\theta_{1}\right) Y_{t}^{D} \\
& c_{D t}^{F}=\theta_{1} Y_{t}^{F} \Rightarrow c_{F t}^{F}=\left(1-\theta_{1}\right) Y_{t}^{F}
\end{aligned}
$$

It is simple to see that when these consumption expressions are assumed, proportionality factors in the consumption rules cancel out, leading exactly to the same expression (26). That means that, so long as countries are following efficient consumption allocations, the exchange rate will be determined by the same variables. 
The intuition for this formula is straightforward. $m_{t+1}^{j}=2^{\gamma^{j}}\left(\exp \left[\sum_{\mathrm{s}=1}^{12} \theta_{S}^{j} \mu_{\mathrm{t}+1}(s)\right] \mathrm{Y}_{\mathrm{t}+1}^{j}\right)^{1-\gamma^{j}}\left(\mathrm{~N}_{\mathrm{t}+1}^{j}\right)^{-1}$, for $j=D, F$, is a function not only of money, goods endowments, but is also a function of the seasonal shifts in preferences. Evidence indicates that $Y_{t+1}^{j}$ and $N_{t+1}^{j}$ show seasonal patterns, however seasonal variation does not exist on $R_{t+1}^{j}$ and $S_{t}$. The introduction of seasonal parameters, $\dot{\theta}_{S}$ (for $j=D, F$ and $S=1,2, \ldots, s$ ) allows the model to smooth the marginal utility of the expected returns from the investment on shares in the face of systematic seasonal fluctuations in $Y_{t+1}^{j}$ and $N_{t+1}^{j}{ }^{7}$

Now, we can consider the economic model to be an approximation to the stochastic processes generating the actual data. If the economic model is correctly specified, it could generate data with similar characteristics to those of the observed data. Expression (26) may be used to compute the exchange rate time series implied by this model and then compare it with real data. The next section describes the way to do this.

\section{Estimation of parameters and empirical evaluation of the seasonal model}

In this section, we evaluate our model analyzing its capacity to generate time series of exchange rates with similar properties to observed exchange rates. We will use a procedure that consists of four steps:

(1) First, we estimate the preference parameters of the model exploiting orthogonality conditions from our model using Hansen's (1982) generalized method of moments (GMM). Theoretical variables are approximated by their observed counterparts. Outputs are approximated by monthly industrial production and monetary

\footnotetext{
${ }^{7}$ To gain some intuition, let's focus on one season in which $Y_{t+1}^{j}$ is relatively low (if $\gamma^{j}>1$ ), then $m_{t+l}^{j}$ will
} be relatively high during this season, unless the seasonal parameter be relatively high to avoid seasonal fluctuations in the marginal utility of expected returns from investment. The taste shifts parameters indicate that the utility obtained from the consumption at time $t$ varies according the prevailing season $S$ and this explain that $m_{t+1}^{j}$ does not track seasonal patterns in $Y_{t+1}^{j}$ and $N_{t+l}^{j}$. Agents improve their welfare avoiding the creation of intertemporal distortions when making their decision to invest. 
aggregates are approximated by M2. Asset returns are generated by taking a first difference on the natural logarithm of the equity price index.

(2) We then use expression (26) to generate theoretical exchange rate time series. The preference parameters are evaluated at their point estimates and the theoretical variables $Y_{t}, M_{t}$ and assets returns are approximated by their observed counterparts.

(3) We analyse the stochastic properties of theoretical exchange rates using BoxJenkins methodology (Box and Jenkins, 1970).

(4) Finally, we compare the stochastic properties of theoretical and observed exchange rates using cointegration analysis.

\section{A. Details of the procedure for estimating preference parameters}

In this section, we briefly describe the estimation procedure. We focus on GMM estimation as implemented for dynamic rational expectations models by Hansen and Singleton (1982). The dynamic optimization problem for an economic agent implies a set of stochastic Euler equations that must be satisfied in equilibrium. These Euler equations in turn imply a set of population orthogonality conditions that depend nonlinearly on variables observed by econometricians and on unknown parameters characterizing preferences. These conditions of orthogonality are used to construct a criterion function whose minimizer is the estimate of parameters.

Though there are many different types of Euler equations for the model specified in the previous section, the parameters are estimated by exploiting expression (19), which may also be written as: ${ }^{8}$

$$
\beta E\left(\frac{U_{c_{D}^{j}}\left(c_{D, t+1}^{D}(s), c_{D, t+1}^{F}(s)\right)\left(P_{t+1}^{j}\right)^{-1}}{U_{c_{D}^{j}}\left(c_{D, t}^{D}(s), c_{D, t}^{F}(s)\right)\left(P_{t}^{j}\right)^{-1}}\left(d_{t+1}^{j}+Q_{t+1}^{j}\right)\left(Q_{t}^{j}\right)^{-1} \mid \mathrm{X}_{\mathrm{t}}\right)=1,
$$

where $X_{t}$ is a vector representing all the information available to the agent at date $t$.

\footnotetext{
${ }^{8}$ The first order conditions derived must hold with respect to all assets. The derivations, however, are carried out only for a single asset for each country.
} 
Estimation using (27) requires the function $U$ to be explicitly parameterized. Therefore, when (23) is substituted in (27):

$$
E\left(\beta\left\{\exp \left(\sum_{s=2}^{12} \theta_{\mathrm{s}}^{j}\left[\mu_{\mathrm{t}+1}(s)-\mu_{\mathrm{t}}(s)\right]\right)\right\}^{1-\gamma^{j}}\left(\frac{c_{D, t+1}^{j}}{c_{D, t}^{j}}\right)^{-\gamma^{j}}\left(\frac{P_{t}^{j}}{P_{t+1}^{j}}\right)\left(\frac{d_{t+1}^{j}+Q_{t+1}^{j}}{Q_{t}^{j}}\right)-1 \mid \mathrm{X}_{\mathrm{t}}\right)=0 .
$$

The nominal price of good $j$, for $j=D, F$, is given by cash-in-advance constraint (7) and assuming pooling equilibria as in (25), expression (28) becomes:

$$
E\left(\beta\left\{\exp \left(\sum_{s=2}^{12} \theta_{\mathrm{s}}^{j}\left[\mu_{\mathrm{t}+1}(s)-\mu_{\mathrm{t}}(s)\right]\right)\right\}^{1-\gamma^{j}}\left(\frac{Y_{t+1}^{j}}{Y_{t}^{j}}\right)^{-\gamma^{j}}\left(\frac{N_{t}^{j}}{N_{t+1}^{j}}\right)\left(\frac{d_{t+1}^{j}+Q_{t+1}^{j}}{Q_{t}^{j}}\right)-1 \mid \mathrm{X}_{\mathrm{t}}\right)=0 .
$$

Expression (29) requires the random variable described by:

$$
\left.\beta\left\{\exp \left(\sum_{\mathrm{s}=2}^{12} \theta_{\mathrm{s}}^{j}\left[\mu_{\mathrm{t}+1}(s)-\mu_{\mathrm{t}}(s)\right]\right)\right\}\right\}^{1-\gamma^{j}}\left(\frac{Y_{t+1}^{j}}{Y_{t}^{j}}\right)^{-\gamma^{j}}\left(\frac{N_{t}^{j}}{N_{t+1}^{j}}\right)\left(\frac{d_{t+1}^{j}+Q_{t+1}^{j}}{Q_{t}^{j}}\right)-1,
$$

to be uncorrelated with any variable contained in the information set $X_{t}$. It should therefore be the case that:

$$
E\left(\left[\beta\left\{\exp \left(\sum_{s=2}^{12} \theta_{\mathrm{s}}^{j}\left[\mu_{\mathrm{t}+1}(s)-\mu_{\mathrm{t}}(s)\right]\right)\right\}^{1-\gamma^{j}}\left(\frac{Y_{t+1}^{j}}{Y_{t}^{j}}\right)^{-\gamma^{j}}\left(\frac{N_{t}^{j}}{N_{t+1}^{j}}\right)\left(\frac{d_{t+1}^{j}+Q_{t+1}^{j}}{Q_{t}^{j}}\right)-1\right] z_{t}\right)=0
$$

where $z_{t}$ is any subset of the information set $X_{t}$ that we are able to observe.

Let $\psi_{o}{ }^{j}=\left\{\beta, \gamma^{j}, \theta_{1}^{j}, \theta_{2}^{j}, \theta_{3}^{j}, \theta_{4}^{j}, \theta_{5}^{j}, \theta_{6}^{j}, \theta_{7}^{j}, \theta_{8}^{j}, \theta_{9}^{j}, \theta_{10}^{j}, \theta_{11}^{j}, \theta_{12}^{j}\right\} \in \mathfrak{R}^{14}$ denote the vector of unknown parameters, for $j=D, F$, that are to be estimated, and let $w_{t+1} \equiv\left(Y_{t+1}^{j}\left(Y_{t}^{j}\right)^{-1}, N_{t+1}^{j}\left(N_{t}^{j}\right)^{-1},\left(d_{t+1}^{j}+Q_{t+1}^{j}\right)\left(Q_{t}^{j}\right)^{-1},\left(\mu_{t+1}(s)-\mu_{t}(s)\right)\right)$ denote the vector of variables that are observed by agents for date $t+1$. Hence, we can define the function $h\left(w_{t+1}, \psi_{0}^{j}\right)$ given by:

$$
h\left(w_{t+1}, \psi_{0}^{j}\right)=\beta\left\{\exp \left(\sum_{s=2}^{12} \theta_{s}^{j}\left[\mu_{\mathrm{t}+1}(s)-\mu_{\mathrm{t}}(s)\right]\right)\right\}^{1-\gamma^{j}}\left(\frac{Y_{t+1}^{j}}{Y_{t}^{j}}\right)^{-\gamma^{j}}\left(\frac{N_{t}^{j}}{N_{t+1}^{j}}\right)\left(\frac{d_{t+1}^{j}+Q_{t+1}^{j}}{Q_{t}^{j}}\right)-1 .
$$


We can interpret (32) $\left(u_{t+1}=h\left(w_{t+1}, \psi_{0}^{j}\right)\right)^{9}$ as the disturbance vector in our econometric estimation, which should have finite second moments and, given (31),

$$
E\left(u_{t+1} \mid \mathrm{X}_{\mathrm{t}}\right)=0
$$

We can now define the criterion function $f$ given by:

$$
f\left(w_{t+1}, z_{t}, \psi_{0}^{j}\right)=h\left(w_{t+1}, \psi_{0}^{j}\right) \otimes z_{t},
$$

where $z_{t}^{10}$ is the $q$ dimensional vector of variables with finite second moments that are in the agent's information set; and $f$ maps $R x R^{q} x R^{14}$ into $R^{q}$ and $\otimes$ is the Kronecker product. Thus, an implication of (33)-(34) and their accompanying assumptions is that

$$
E\left[f\left(w_{t+1}, z_{t}, \psi_{0}^{j}\right)\right]=0
$$

Equation (35) represents a set of $q$ population orthogonality conditions from which an estimator of $\psi_{0}{ }^{i}$ may be obtained, provided that $q$ is at least as large as the number of unknown parameters.

We proceed by constructing an objective function that depends only on available sample information and the unknown parameters. Let $g\left(\psi^{j}\right)=E\left[f\left(w_{t+1}, z_{t}, \psi^{j}\right)\right]$, where $\psi^{j} \in \mathfrak{R}^{14}$. Note that (35) implies that $g\left(\psi^{j}\right)$ has a zero at $\psi^{j}=\psi_{0}{ }^{j}$. Thus, the GMM estimator of $g\left(\psi^{j}\right)$

$$
g_{T}\left(\psi^{j}\right)=\frac{1}{T} \sum_{t=1}^{T} f\left(w_{t+1}, z_{t}, \psi^{j}\right)
$$

\footnotetext{
${ }^{9}$ The utility function assumed in (23) is additively separable over time and additively separable in domestic
} and foreign goods. This assumption allows us to estimate seasonal taste parameters, factor discount and intertemporal elasticity of substitution parameters using single equation methods for each good. This can be seen by noting that in (32), $u_{t+l}$ is a function only of the variables $Y_{t}^{j}, M_{t}^{j}$ and asset returns corresponding to country $j(=\mathrm{D}, \mathrm{F})$.

${ }^{10}$ The instruments are: a constant term, lagged production growth rates, lagged monetary aggregates growth rates, and lagged rates of return:

$z_{t}=\left\{1, Y_{t} / Y_{t-1}, \cdots, Y_{t-l+1} / Y_{t-l}, M_{t} / M_{t-l}, \cdots, M_{t-l+1} / M_{t-l}, \log \left(Q_{t} / Q_{t-1}\right), \cdots, \log \left(Q_{t-l+1} / Q_{t-l}\right)\right\}$. 
evaluated at $\psi^{j}=\psi_{0}{ }^{j}, g_{T}\left(\psi_{0}{ }^{j}\right)$, should be close to zero for large values of $T$. Given this fact, it is reasonable to select the $\psi^{j}$ that makes $g_{T}\left(\psi^{j}\right)$ "close" to zero. Therefore, a GMM estimator of $\psi_{0}^{j}$ can be obtained by minimizing the quadratic form

$$
J_{T}\left[\psi^{j}\right]=\left[g_{T}\left(\psi^{j}\right)\right]^{\prime} W_{T}\left[g_{T}\left(\psi^{j}\right)\right]
$$

where $W_{T}$ is a $q$ by $q$ symmetric positive definite matrix that can depend on sample information. An important aspect of specifying a GMM problem is the choice of the weighting matrix. We use the optimal $W_{T}=\hat{\Omega}^{-1}$, where $\hat{\Omega}^{-1}$ is the estimated covariance matrix of the sample moments $q$.We use consistent Two-Stage least square estimates for the initial estimate of $\psi_{0}^{j}$ in forming the estimate of $\Omega .^{11}$

\section{Estimation}

To estimate $\psi_{0}{ }^{j}$, we use monthly seasonally unadjusted data from 1986:01 to 1998:04 for five countries: Germany (GM), Spain (SP), Japan (JP), the United Kingdom (UK), and the United States (US). Outputs are approximated by the corresponding monthly industrial production (IP), monetary aggregates by the corresponding M2, and asset returns are generated by taking a first difference on the natural logarithm of the equity price index. Appendix 1 describes the data and their stochastic properties. ${ }^{12}$

Table 1 shows the GMM estimation of $\psi_{0}^{j}$. The seasonal taste coefficients $\theta_{s}^{j}$, for $s=1,2,3, \ldots, 11$, and $j=G M, S P, J P, U K, U S$ indicate how the model seasonally adjusts consumption levels in month $s$ relative to December for the good produced in country $j$. December is chosen as a reference month $\left(\theta_{12}^{j}=1\right)$. Seasonal taste parameters are statistically significant in several cases: January, February, July, August, October, November for GM; in the case of SP all the seasonal parameters are statistically

\footnotetext{
${ }^{11}$ We use Heteroskedasticity and an Autocorrelation Consistent Covariance Matrix of the sample moments.

${ }^{12}$ Hansen (1982) showed that sufficient conditions for the asymptotic properties of the GMM include strict
} stationarity of the data. Strict stationarity may be violated for some kinds of seasonal variation. However, consistency and asymptotic normality of the estimators and the asymptotic distribution of the test statistic can be demonstrated under weaker conditions. See Jagannathan (1983) and Lim (1985) for an analysis of the asymptotic properties of the GMM under seasonality and non-stationarity. Stationarity may also be violated under some models of growth rates of real outputs or monetary aggregates. In our empirical study, these growth rates are stationary. 
significant; January, February, March, May, August for JP; March, October and November for UK; and all the seasonal parameters are significant, except February, April and July, for US. The fact that seasonal preference shocks are significantly different from zero means that these shocks must be included in order to explain the joint behavior of consumption and asset returns. The point estimates are intuitively plausible. We would expect values of $\theta_{s}^{j}>0$ for months with a low level of income relative to December to avoid seasonal fluctuations in the marginal utility of expected returns from investment. For instance, Spanish $\mathrm{IP}^{13}$ exhibits evident signs of seasonality, with a low value in December (reference month) and a deep trough in August. For Spain all seasonal preference parameters are negative, except $\theta_{8}^{S P}=0.344$, corresponding to August, which is a month of low work hours due to holidays, and therefore low output.

The estimates of $\gamma^{j}$ are similar to those found in other studies, ranging from 0.74 to $2.42 .{ }^{14}$ In order to test the validity of overidentifying restrictions, Hansen's (1982) Jstatistics are also displayed. The null hypothesis (overidentifying restrictions are satisfied) is not rejected at a $5 \%$ significance level in any case. ${ }^{15}$

${ }^{13}$ In this paper, theoretical output is approximated by the corresponding monthly industrial production (IP)

${ }^{14}$ In their study of aggregate fluctuations, Kydland and Prescott (1982) found that they needed a value of between one and two to mimic the observed relative variability of consumption and investment. Altug (1983) estimates the parameter at near zero. Kehoe (1983), studying the response of small countries' balance of trade to terms of trade shocks, obtains estimates near one. Hildreth and Knowles (1986), in their study of the behavior of farmers, also obtain estimates between one and two. Mehra and Prescott (1985) present evidence for restricting the value of relative risk aversion to a maximum of ten, though without specifying a concrete value. Eichenbaum et. al. (1984), Mankiw et al. (1985) and Hansen and Singleton (1982) report values of $\gamma$ between zero and one. Mankiw (1985) reports values of between 2 and 4.

15 Note that preferences given by expressions (23) and (24) assume that seasonal taste coefficients vary across domestic and foreign goods. The risk aversion for each good is also different. So the finding of different $\theta_{s}^{j}$ and $\gamma^{j}$ for goods produced in different countries does not contradict the assumption of identical preferences. 
Table 1: GMM estimation of utility function parameters ${ }^{\text {(a) }}$

\begin{tabular}{|c|c|c|c|c|c|c|c|c|c|c|c|c|c|}
\hline & $\theta_{1}{ }^{(\mathrm{c})(\mathrm{d})}$ & $\theta_{2}$ & $\theta_{3}$ & $\theta_{4}$ & $\theta_{5}$ & $\theta_{6}$ & $\theta_{7}$ & $\theta_{8}$ & $\theta_{9}$ & $\theta_{10}$ & $\theta_{11}$ & $\gamma$ & $\mathrm{J} \_\mathrm{Sta}^{(\mathrm{e})(\mathrm{f})}$ \\
\hline$\theta_{s}^{\mathrm{GM}(\mathrm{b})}$ & $\begin{array}{l}0.130^{*} \\
(0.06)\end{array}$ & $\begin{array}{l}0.121 * * \\
(0.07)\end{array}$ & $\begin{array}{l}0.033 \\
(0.08)\end{array}$ & $\begin{array}{l}0.112 \\
(0.09)\end{array}$ & $\begin{array}{l}0.125 \\
(0.08)\end{array}$ & $\begin{array}{l}0.079 \\
(0.08)\end{array}$ & $\begin{array}{l}0.156^{* * *} \\
(0.09)\end{array}$ & $\begin{array}{l}0.270^{*} \\
(0.12)\end{array}$ & $\begin{array}{l}0.066 \\
(0.09)\end{array}$ & $\begin{array}{l}-0.061^{*} \\
(0.09)\end{array}$ & $\begin{array}{l}\text { *-0.022* } \\
(0.05)\end{array}$ & $\begin{array}{l}1.31^{*} \\
(0.18)\end{array}$ & $\begin{array}{l}29.52 \\
(0.10)\end{array}$ \\
\hline$\theta_{s}^{\mathrm{SP}}$ & $\begin{array}{l}-0.115^{*} \\
(0.03)\end{array}$ & $\begin{array}{l}-0.153^{*} \\
(0.05)\end{array}$ & $\begin{array}{l}-0.255^{*} \\
(0.06)\end{array}$ & $\begin{array}{l}-0.262^{*} \\
(0.08)\end{array}$ & $\begin{array}{l}-0.349^{*} \\
(0.10)\end{array}$ & $\begin{array}{l}-0.328^{*} \\
(0.09)\end{array}$ & $\begin{array}{l}-0.264 * \\
(0.08)\end{array}$ & $\begin{array}{l}0.344 * \\
(0.06)\end{array}$ & $\begin{array}{l}-0.106^{* *} \\
(0.05)\end{array}$ & $\begin{array}{l}-0.133^{*} \\
(0.05)\end{array}$ & $\begin{array}{c}*-0.139 * \\
(0.04)\end{array}$ & $\begin{array}{l}0.74^{*} \\
(0.08)\end{array}$ & $\begin{array}{l}27.06 \\
(0.76)\end{array}$ \\
\hline$\theta_{s}^{\mathrm{JP}}$ & $\begin{array}{l}0.139 * \\
(0.03)\end{array}$ & $\begin{array}{l}0.107 * \\
(0.05)\end{array}$ & $\begin{array}{l}-0.038^{*} \\
(0.03)\end{array}$ & $\begin{array}{l}0.090 \\
(0.03)\end{array}$ & $\begin{array}{l}0.154^{*} \\
(0.07)\end{array}$ & $\begin{array}{l}0.019 \\
(0.04)\end{array}$ & $\begin{array}{l}0.032 \\
(0.05)\end{array}$ & $\begin{array}{l}0.137 * \\
(0.05)\end{array}$ & $\begin{array}{l}0.012 \\
(0.05)\end{array}$ & $\begin{array}{l}0.003 \\
(0.04)\end{array}$ & $\begin{array}{l}-0.005 \\
(0.02)\end{array}$ & $\begin{array}{l}1.51^{*} \\
(0.41)\end{array}$ & $\begin{array}{l}18.45 \\
(0.68)\end{array}$ \\
\hline$\theta_{\mathrm{s}}^{\mathrm{UK}}$ & $\begin{array}{l}0.047 \\
(0.05)\end{array}$ & $\begin{array}{l}0.012 \\
(0.06)\end{array}$ & $\begin{array}{l}-0.182 * \\
(0.06)\end{array}$ & $\begin{array}{l}-0.063 \\
(0.06)\end{array}$ & $\begin{array}{l}-0.112 \\
(0.08)\end{array}$ & $\begin{array}{l}-0.151 \\
(0.09)\end{array}$ & $\begin{array}{l}-0.003 \\
(0.07)\end{array}$ & $\begin{array}{l}0.096 \\
(0.06)\end{array}$ & $\begin{array}{l}-0.053 \\
(0.06)\end{array}$ & $\begin{array}{l}-0.118^{*} \\
(0.05)\end{array}$ & $\begin{array}{l}\text { * }-0.106 * \\
(0.03)\end{array}$ & $\begin{array}{l}1.22^{*} \\
(0.11)\end{array}$ & $\begin{array}{l}20.97 \\
(0.52)\end{array}$ \\
\hline$\theta_{\mathrm{s}}{ }^{\mathrm{US}}$ & $\begin{array}{l}0.022 * \\
(0.004)\end{array}$ & $\begin{array}{l}0.001 \\
(0.004)\end{array}$ & $\begin{array}{c}-0.007 * \\
(0.003)\end{array}$ & $\begin{array}{l}-0.002 \\
(0.004)\end{array}$ & $\begin{array}{l}0.017^{*} \\
(0.005)\end{array}$ & $\begin{array}{l}-0.034 * \\
(0.004)\end{array}$ & $\begin{array}{l}0.001 \\
(0.005)\end{array}$ & $\begin{array}{l}-0.031^{*} \\
(0.004)\end{array}$ & $\begin{array}{l}-0.042 * \\
(0.003)\end{array}$ & $\begin{array}{l}-0.037^{*} \\
(0.003)\end{array}$ & $\begin{array}{l}*-0.014 * \\
(0.001)\end{array}$ & $\begin{array}{l}2.42^{*} \\
(0.036)\end{array}$ & $\begin{array}{l}25.83 \\
(0.81)\end{array}$ \\
\hline
\end{tabular}

(a) The instruments are: a constant term, lagged production growth rates, lagged monetary aggregates growth rates, and lagged rates of return.

(b) Germany (GM), Spain (SP), Japan (JP), United Kingdom (UK), United States (US)

(c) Estimated standard errors in brackets

(d) Statistical significance is indicated by a single asterisk $(*)$ for the $5 \%$ level, and a double asterisk $(* *)$ for the $10 \%$ level

(e) J-statistic, for testing the validity of overidentifying restrictions. Under the null hypothesis, the overidentifying restrictions are satisfied, the J-statistic (i.e. the minimized value of the objective function) times the number of observations is asymptotically $\chi_{q}^{2}$, with degrees of freedom equal to the number of overidentifying restrictions

(f) $\mathrm{P}$ values represented in brackets.

Figures 1-5, in Appendix 2, show the residual graphs, autocorrelation function $(\mathrm{ACF})$ and partial autocorrelation function (PACF) associated with GMM equations. Residuals are white noise.

\section{B- Stochastic properties of theoretical and observed exchange rates}

We restrict our testing strategy to the model implications in the statistical properties of the exchange rate. Once the entire parameters vector $\psi_{0}{ }^{j}$ is estimated, using the corresponding IP, M2 and the returns on assets, we generate several theoretical monthly time series implied by expression (26), evaluated at the point estimates of the utility function parameters of Table 1: German mark (DEM/USD) ${ }^{16}$, Japanese yen (JPY/USD), Spanish peseta (ESP/USD), and British pound (GBP/USD) relative to the US dollar, as well as Japanese yen (JPY/DEM), Spanish peseta (ESP/DEM), and British pound (GBP/DEM) relative to the German mark.

16 The currency is calculated as the value of the second country's currency. For example, (GBP/USD) is the number of British pounds needed to purchase a US dollar; in this case the UK is the domestic country and the USA the foreign country. 
Table 2 reports a variety of descriptive statistics of the theoretical exchange rate, (ThtExRa) and the observed exchange rate (ObsExRa) over the sample period 1990:011998:04. ${ }^{17}$ Mean (M), standard deviation (Std) and the order of integration (d). The stochastic process of the ThtExRa time series is then analyzed and compared with the stochastic processes characterizing the ObsExRa. Table 2 shows time series analysis results; diagnostic checks are developed to detect model inadequacy. Descriptive statistic to test for serial correlation in the residuals from estimated models are reported: Ljung-Box Q-statistics at lag $12(\mathrm{Q}(12))$.

Table 2: Summary of ARIMA ${ }^{18}$ models fitted to the ThtExRa and the ObsExRa

\begin{tabular}{|c|c|c|c|c|c|}
\hline & $\mathrm{M}$ & Std. & $\nabla^{\mathrm{d}}$ & $\mathrm{Q}(12)$ & ARIMA MODELS $^{(\mathrm{a})(\mathrm{b})}$ \\
\hline Obs DEM/USD & $1.6^{*} 10^{0}$ & $1.2 * 10^{-1}$ & $\nabla$ & 9.7 & $\mathrm{Y}_{\mathrm{t}}=0.20 \xi_{\mathrm{t}}^{\mathrm{S} 3 / 91}+\mathrm{N}_{\mathrm{t}}$ \\
\hline Tht DEM/USD & $2.1 * 10^{-4}$ & $1.9 * 10^{-5}$ & $\nabla$ & 12.6 & $\begin{array}{l}\left(1-0.16 \mathrm{~B}+0.32 \mathrm{~B}^{2}\right) \nabla \mathrm{Y}_{\mathrm{t}}=\mathrm{a}_{\mathrm{t}} \\
(0.10)(0.10)\end{array}$ \\
\hline Obs ESP/USD & $1.2 * 10^{2}$ & $1.6 * 10$ & $\nabla$ & 0.9 & $\begin{aligned} \mathrm{Y}_{\mathrm{t}}= & (7.5+10.2 \mathrm{~B}) \xi_{\mathrm{t}}^{\mathrm{S} 9 / 92}+12.7 \xi_{\mathrm{t}}^{\mathrm{I} / 93}+\mathrm{N}_{\mathrm{t}} \quad \nabla \mathrm{N}_{\mathrm{t}}=\mathrm{a}_{\mathrm{t}} \\
& (3.5)(3.5)\end{aligned}$ \\
\hline Tht ESP/USD & $6.8 * 10^{-4}$ & $8.1 * 10^{-5}$ & $\nabla$ & 18.4 & $\begin{array}{l}\left(1+0.52 \mathrm{~B}+0.15 \mathrm{~B}^{2}+0.23 \mathrm{~B}^{4}\right) \nabla \mathrm{Y}_{\mathrm{t}}=\mathrm{a}_{\mathrm{t}} \\
(0.10)(0.11) \quad(0.10)\end{array}$ \\
\hline Obs GBP/USD & $6.1 * 10^{-1}$ & $4.6^{*} 10^{-2}$ & $\nabla$ & 6.6 & $\begin{aligned} \mathrm{Y}_{\mathrm{t}}= & (0.08+0.08 \mathrm{~B}) \xi_{\mathrm{t}}^{\mathrm{S} 1092}+\mathrm{N}_{\mathrm{t}} \\
& (0.02)(0.02)\end{aligned}$ \\
\hline Tht GBP/USD & $4.6 * 10^{-5}$ & $4.4^{*} 10^{-6}$ & $\nabla$ & 10.9 & $\begin{array}{l}\left(1-0.37 \mathrm{~B}+0.25 \mathrm{~B}^{2}+0.18 \mathrm{~B}^{4}\right) \nabla \mathrm{Y}_{\mathrm{t}}=\mathrm{a}_{\mathrm{t}} \\
(0.10)(0.10) \quad(0.10)\end{array}$ \\
\hline Obs JPY/USD & $1.2 * 10^{2}$ & $1.7 * 10$ & $\nabla$ & 22.4 & $\begin{array}{l}\mathrm{Y}_{\mathrm{t}}=-10.5 \xi_{\mathrm{t}}^{\mathrm{S} 5 / 97}+\mathrm{N}_{\mathrm{t}} \\
(3.59)\end{array}$ \\
\hline Tht JPY/USD & $2.1 * 10^{-6}$ & $3.5 * 10^{-7}$ & $\nabla$ & 18.7 & $\begin{array}{l}(1+0.35 \mathrm{~B}) \nabla \mathrm{Y}_{\mathrm{t}}=\mathrm{a}_{\mathrm{t}} \\
(0.09)\end{array}$ \\
\hline Obs ESP/DEM & $7.6 * 10$ & $1.0 * 10$ & $\nabla$ & 12.6 & 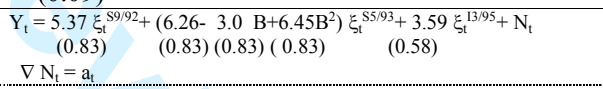 \\
\hline Tht ESP/DEM & $0.3 * 10$ & $1.6^{*} 10^{-1}$ & $\nabla$ & 14.5 & $\begin{array}{l}\left(1+0.64 \mathrm{~B}+0.27 \mathrm{~B}^{2}+0.29 \mathrm{~B}^{3}\right) \nabla \mathrm{Y}_{\mathrm{t}}=\mathrm{a}_{\mathrm{t}} \\
(0.10)(0.11) \quad(0.10)\end{array}$ \\
\hline Obs GBP/DEM & $3.8 * 10^{-1}$ & $4.0^{*} 10^{-2}$ & $\nabla$ & 6.55 & $\begin{array}{l}(1+0.25 B) \nabla Y_{t}=a_{t} \\
(0.09)\end{array}$ \\
\hline Tht GBP/DEM & $2.2 * 10^{-1}$ & $6.6^{*} 10^{-3}$ & $\nabla$ & 10 & $\begin{array}{l}\left(1-0.21 \mathrm{~B}+0.41 \mathrm{~B}^{2}\right) \nabla \mathrm{Y}_{\mathrm{t}}=\mathrm{a}_{\mathrm{t}} \\
(0.10)(0.10)\end{array}$ \\
\hline Obs JPY/DEM & $7.4 * 10$ & $0.9 * 10$ & $\nabla$ & 8.5 & $\nabla \mathrm{Y}_{\mathrm{t}}=\mathrm{a}_{\mathrm{t}}$ \\
\hline Tht JPY/DEM & $9.7 * 10^{-3}$ & $1.0^{*} 10^{-3}$ & $\nabla$ & 17.3 & $\begin{array}{l}\left(1+0.34 \mathrm{~B}+0.22 \mathrm{~B}^{2}\right) \nabla \mathrm{Y}_{\mathrm{t}}=\mathrm{a}_{\mathrm{t}} \\
(0.10)(0.11) \quad(0.10)\end{array}$ \\
\hline
\end{tabular}

(a) Estimated standard errors in brackets

(b) $\xi_{t}^{I " T "}=\left\{\begin{array}{ll}1 & t=T \\ 0 & t \neq T\end{array} ; \quad \xi_{t} T^{\prime \prime}= \begin{cases}1 & t \geq T \\ 0 & t<T\end{cases}\right.$

${ }^{17}$ Preference parameters were estimated with the whole sample; nonetheless, we analyze this shorter period in order to compare with Jimenez and Flores (2004) results.

${ }^{18}$ Autoregressive Integrated Moving Average (ARIMA) Model 
The stochastic processes for all currencies (observed and theoretical) are modeled in first differences. Outliers in ObsExRa are analyzed to conclude that the random walk process is a valid representation for six out of the seven analyzed cases. The first difference in the GBP/DEM time series behaves as a first order autoregressive process.

ThtExRa is generated by expression (26) using seasonally unadjusted data (IP and M2); seasonality in these variables is controlled in the model. The time series analysis shows that autocorrelation of ThrExRa at the seasonal lag does not exist, as in the autocorrelation of ObsExRa. Figures 6-12 in Appendix 3 plot monthly data from 1990:01 to 1998:04 for both theoretical and observed exchange rates. ${ }^{19}$

\section{C.- Cointegration analysis}

The fourth column in Table 2 shows that ObsExRa and ThtExRa time series follow integrated processes of order 1 [I(1)]; given this result we can test for cointegration. We use the simplest procedure, sometimes called the Engle-Granger or EG test (Engle and Granger, 1987), which involves first using OLS to estimate the following cointegration regression:

$$
O b s E x R a_{t}=\beta_{0}+\beta_{1} T h t E x R a_{t}+u_{t}^{E x R a},
$$

and then using an ordinary Dickey Fuller test based on the regression:

$$
\nabla u_{t}^{E x R a}=\mu+(1-\alpha) u_{t}^{E x R a}+\varepsilon_{t} .
$$

${ }^{19}$ Empirical results do not show any increased ability of the model to explain exchange rate volatility. Volatility of the simulated exchange rate series is orders of magnitude smaller that the volatility of the actual exchange rate series. The analysis including non-traded goods or assuming market segmentation would increase the capacity of this model to replicate high volatility in exchange rates, but to obtain closed-form solutions for the exchange rate and make the model amenable to intuition and empirical research, we assume that prices are flexible and PPP holds at every point. The paper must be viewed as a first attempt to incorporate seasonal preferences into a flexible price equilibrium model of exchange rate. While it may not have resolved all the equilibrium model problems, the development of more generalized preference structure allow us to replicate some stochastic properties of the actual exchange rate for some currencies: (1) no seasonal fluctuation and (2) degree of integration equal to one. 
Since serial correlation may be a problem, it is more common to use an Augmented Engle-Granger or AEG test, which is related to the EG test in the same way as the ADF test is related to the ordinary DF test. If $\mathrm{u}_{\mathrm{t}}^{E x R a}$ is $\mathrm{I}(0)$, regression (38) implies that the variables ObsExRa and ThtExRa will be cointegrated with the cointegrating vector $\left(1,-\beta_{1}\right)$.

We also perform a cointegration test using the Trace (Tr_ST) and Maximun eigenvalue (MaxAu_ST) tests developed by Johansen $(1991,1992)$. Table 3 shows the results.

Within this framework, cointegration means that the economic model replicates the long-run evolution of the actual exchange rate. Moreover, if the OLS estimate of $\beta_{1}$ in (38) is positive, the economic model subsequently also replicates the appreciation or depreciation process in the observed time series.

Table 3. Testing for cointegration between $O b s E x R a$ and ThtExRa.

\begin{tabular}{|c|c|c|c|c|c|c|c|c|c|}
\hline \multirow[b]{2}{*}{ ExRa } & \multicolumn{4}{|c|}{ AEG } & \multicolumn{2}{|c|}{ Tr_ST ${ }^{(c)}$} & \multicolumn{2}{|c|}{ MaxAu_ST } & \multirow[b]{2}{*}{ Lag } \\
\hline & $\beta_{0}{ }^{(\mathrm{a})}$ & $\beta_{1}$ & $\tau_{\mu}^{\left({ }^{(b)}\right.}$ & Lag & $\mathrm{H}_{0}: \mathrm{r}=0$ & $\mathrm{H}_{0}: \mathrm{r} \leq 1$ & $\mathrm{H}_{0}: \mathrm{r}=0$ & $\mathrm{H}_{0}: \mathrm{r} \leq 1$ & \\
\hline DEM/USD & $\begin{array}{l}0.2 * 10 \\
(0.1 * 10)\end{array}$ & $\begin{array}{l}-1.5^{*} 10^{3} \\
\left(0.6^{*} 10^{3}\right)\end{array}$ & -2.54 & 1 & 7.60 & 0.74 & 6.87 & 0.74 & 2 \\
\hline ESP/USD & $\begin{array}{l}17 * 10^{2} \\
(0.8 * 10)\end{array}$ & $\begin{array}{l}-9.3 * 10^{4} \\
\left(1.1 * 10^{4}\right)\end{array}$ & -2.32 & 5 & 7.62 & 1.25 & 6.36 & 1.25 & 1 \\
\hline GBP/USD & $\begin{array}{l}2.0 * 10^{-1} \\
\left(0.4 * 10^{-1}\right)\end{array}$ & $\begin{array}{l}6.6^{*} 10^{3} \\
\left(0.8^{*} 10^{3}\right)\end{array}$ & $-3.26^{* *}$ & 0 & $15.66^{* *}$ & 2.53 & $12.83^{* *}$ & 2.53 & 1 \\
\hline JPY/USD & $\begin{array}{l}8.4 * 10 \\
(1.0 * 10)\end{array}$ & $\begin{array}{l}1.6^{*} 10^{7} \\
\left(0.5^{*} 10^{7}\right)\end{array}$ & -1.21 & 0 & 6.56 & 2.44 & 4.13 & 2.44 & 1 \\
\hline ESP/DEM & $\begin{array}{l}2.0 * 10^{2} \\
\left(0.2 * 10^{2}\right)\end{array}$ & $\begin{array}{l}-3.9 * 10 \\
(0.5 * 10)\end{array}$ & $-3.23^{* *}$ & 10 & $29.35^{*}$ & 3.91 & $25.45^{*}$ & 3.90 & 1 \\
\hline GBP/DEM & $\begin{array}{l}8.4 * 10^{-1} \\
\left(1.2 * 10^{-1}\right)\end{array}$ & $\begin{array}{l}-0.2 * 10 \\
(0.6 * 10)\end{array}$ & -1.79 & 0 & 8.41 & 1.80 & 6.62 & 1.80 & 2 \\
\hline JPY/DEM & $\begin{array}{l}1.3 * 10 \\
(0.6 * 10)\end{array}$ & $\begin{array}{l}6.3 * 10^{3} \\
\left(0.6 * 10^{3}\right)\end{array}$ & -2.80 & 1 & 9.59 & 1.70 & 7.89 & 1.70 & 2 \\
\hline
\end{tabular}

(a) Estimated standard errors in brackets

(b) $\tau_{\mu}$ are computed in exactly the same way as the ordinary t statistic for $\alpha-1=0$ in regression (39). The lag length ( $\mathrm{Lag}$ ) of the lagged difference terms of the dependent variable on the right hand side of (39) is determined using the Akaike information criterion (AIC). Maximum number of lag $=12$. Critical values for the AEG test are taken from Davidson and MacKinnon (1993). -3.90 (1\%), -3.34 (5\%), -3.04 (10\%). Statistical significance is indicated by a single asterisk (*) for the $5 \%$ level, and a double asterisk $(* *)$ for the $10 \%$ level.

(c) The system variables are (ObsExRa and ThtExRa). The lag value indicates the order of the vector error correction model (VECM) estimated for each currency, which is determined using the Akaike information criterion (AIC). The asymptotic critical values (without a constant in the data generating process, although the cointegrating equations have intercepts) obtained from Osterwald-Lenum (1992) are presented in the following table, in which p is the number of system variables and $\mathrm{h}$ is the number of cointegration relations under the null hypothesis. Trz are the critical values for Johansen's likelihood ratio test of the null hypothesis of $h$ cointegration relations against the alternative of $N O$ restrictions. Max are the critical values for Johansen's likelihood ratio test of the null hypothesis of $h$ cointegration relations against the alternative of $h+1$ relations. Statistical significance is indicated by a single asterisk $(*)$ for the $5 \%$ level, and a double asterisk $(* *)$ for the $10 \%$ level.

\begin{tabular}{|c|c|c|c|c|}
\hline \multicolumn{5}{|c|}{ Asymptotic critical values } \\
\hline & $\mathrm{p}-\mathrm{h}$ & $1 \%$ & $5 \%$ & $10 \%$ \\
\hline & 1 & 11.57 & 8.08 & 6.69 \\
\hline & 2 & 21.96 & 17.84 & 15.58 \\
\hline
\end{tabular}




$$
\operatorname{Max} \mid \begin{array}{llll}
1 & 11.58 & 8.08 & 6.69 \\
2 & 18.78 & 14.59 & 12.78
\end{array}
$$

Test results are mixed:

1.- At the $10 \%$ critical value, the $\tau_{c}$ statistic in Table 3 suggests that estimated residuals $\hat{\mathrm{u}}_{\mathrm{t}}^{\mathrm{GBP} / \mathrm{USD}}$ are $\mathrm{I}(0)$. Johansen tests also provide evidence of cointegration among the ObsExRa and ThtExRa time series at the $10 \%$ critical value. Additionally, as $\beta_{1}$ is positive for this currency in regression (38), the economic model also replicates the appreciation or depreciation observed in the actual time series. Figure 7 in Appendix 3 shows the ObsExRa and ThtExRa time series.

2.- The AEG and Johansen tests reported in Table 3 for the ESP/DEM exchange rate suggests, at the $10 \%$ significance level, that observed and theoretical time series appear to be cointegrated, but $\hat{\beta}_{1}<0$; i.e. the economic model forecasts an appreciation when real data shows depreciation. The ESP/DEM exchange rate shows outliers in 10/92 and 5/93 due to the European Monetary System crisis. However, an intervention analysis reveals that cointegration tests were not distorted.

3.- For the remaining currencies, the tests fail to reject the null hypothesis of no cointegration at the $10 \%$ significance level. In these cases, although the economic model is able to remove seasonality from the exchange rate, it is not able to replicate other important features related to long-run evolution.

\section{Conclusions}

Perhaps the most important characteristic of equilibrium models of the exchange rate is that they enable the discussion of evidence on the predictability of exchange rates from fundamental variables. Exchange rate equilibrium models illustrate how fundamental variables may affect the dynamics of the exchange rate. These models generate equilibrium pricing functions relating the exchange rate to real production, monetary aggregates and asset returns. However, no previous studies have explored the idea of developing a equilibrium model of exchange rate consistent with the data: 
seasonality is inherent in the fundamental variables determining the theoretical exchange rate, but seasonality does not appear in the exchange rate.

This paper generalizes standard dynamic equilibrium models by allowing for seasonal shocks in preferences. In contrast with prior studies, the theoretical model is tested directly with seasonal unadjusted data. We found that the model with seasonal shocks in preferences explains how agents smooth seasonal movements in fundamental variables when they make their decisions to invest. Our model is able to reproduce the stochastic process of the actual exchange rate for some currencies: (1) no seasonal fluctuation and (2) degree of integration equal to one. For instance, in the case of the GBP/USD rate, the model captures the long-term patterns and the depreciation found in the data.

We view the result of this paper as providing a certain counterbalance to the bleak view in relation to the usefulness of the equilibrium model of exchange rate determination. We have focused on a simple, basic equilibrium exchange rate model, but we believe this to be a valuable contribution by setting a benchmark. 


\section{Acknowledgements}

We thank A Novales, L. Puch, J. Ruiz and T. Sinclair for their helpful comments. We have benefited from comments from seminar participants at the Unit Root and Cointegration Testing Conference. We would like to acknowledge the financial support of the Ministerio de Educación, Spain, through Project BEC200303965 and the Fundacion Caja Madrid. Some of this work was conducted while J. A. Jimenez-Martin was visiting the Department of Economics at the George Washington University, Washington, DC.

\section{References}

Altug, S., (1983) Gestation lags and the business cycle: an empirical analysis, CarnegieMellon Working Paper, presented in The Econometric Society meeting, Stanford University, Carnegie-Mellon University, Pittsburgh, PA.

Box, G.E.P. and Jenkins, G. M. (1970) Time Series Analysis, Forecasting and Control, ed. Holden-Day, San Francisco.

Box, G. E. P. and Tiao, G. C. (1975) Intervention analysis with applications to economic and environmental problems, Journal of American Statistical Association, 70, 70-79.

Cole, H. and Obstfeld, M. (1991) Commodity Trade and International Risk Sharing: How Much Do Financial Markets Matter? Journal of Monetary Economics, 28, $3-24$.

Davidson, R. and MacKinnon, J.G. (1993), Estimation and Inference in Econometrics, Oxford University Press, New York.

Eichenbaum, M. S., Hansen, L. P. and Singleton, K. J. (1984) A time series analysis of representative agent models of consumption and leisure choice under uncertainty, mimeo, Pittsburgh, Carnegie-Mellon University.

Engle, R. and Granger, C. (1987) Co-integration and error correction: representation, estimation, and testing, Econometrica, 55, 251-276.

Grilli, V. and Roubini, N. (1992) Liquidity and exchange rates, Journal of International Economics, 33, 339-352.

Ferson, W. E. and Harvey, C. (1992) Seasonality and consumption-based asset pricing, The Journal of Finance, 47, 511-552. 
Hansen, L. (1982) Large sample properties of generalized method of moments estimators, Econometrica, 50, 1029-1084.

Hansen, L. P. and Singleton, K. J. (1982) Generalized instrumental variables estimation of nonlinear rational expectations models, Econometrica, 50 (5), 1269-1286.

Hildreth, C. and Knowles, G. J. (1986) Farmers' Utility Functions, in Bayesian Inference and Decision Techniques: Essays in Honor of Bruno of Finetti. Studies in Bayesian Econometrics and Statistics Series, 6, Amsterdam and Oxford: North-Holland; distributed in the U.S. and Canada by Elsevier Science, New York, in Goel, P. and Zellner, A. (ed.), 291-317.

Jagannathan, R. (1983) Three essays on the pricing of derivative claims, Doctoral Dissertation, Carnegie Mellon University.

Jiménez, J. A. and Flores, R. (2004) The Fit of dynamic equilibrium models of exchange rate, Universidad Complutense of Madrid, Working Paper 04/11, http://www.ucm.es/BUCM/cee/icae/doc/0411.pdf.

Johansen, S. (1992) Statistical analysis of cointegrated vectors, Journal of Economic Dynamics and Control, 12, 231-54, June-September.

(1991) Estimation and hypothesis testing of cointegrating vectors in gaussian vector autoregressive models, Econometrica, 59, 1551-80.

Kehoe, T. (1983) Dynamics of the current account: theoretical and empirical analysis, Working Paper, Harvard University, Cambridge, MA.

Kydland, F. E. and Prescott, E. C. (1982) Time to build and aggregate fluctuations, Econometrica, 50, 1345-1370.

Lim, K. G. (1985) Estimating and testing rational expectations models under nonstationarity, Doctoral Dissertation, Stanford University.

Lucas, R. E. Jr. (1990) Liquidity and Interest Rates, Journal of Economic Theory, 50, 237-264

Lucas, R. E. Jr. (1982) Interest Rates and Currency Prices in a Two-Country World, Journal of Monetary Economics, 10, 335-359.

Lucas, R. E. Jr. (1978) Asset Prices in an Exchange Economy, Econometrica, 46, 142945.

Mankiw, N. G. (1985) Consumer durables and the real interest rate, Review of Economics and Statistic, 67, 353-362.

Mankiw, N. G., Rotemberg, J. J. and Summers, L. H. (1985) Intertemporal substitution in macroeconomics, Quarterly Journal of Economics, 100, 225-251. 
Mehra, R. and Prescott, E. C. (1985) The equity premium: a puzzle, Journal of Monetary Economics, 15, 145-161.

Miron, A. J. (1986) Seasonal fluctuations and the life cycle-permanent income model of consumption, Journal of Political Economy, 94, 1258-1279.

Osterwald-Lenum, M. (1992) A note with quantiles of the asymptotic distribution of the maximum likelihood cointegration rank test statistics, Oxford Bulletin of Economics and Statistics, 54, 461-472

Wallis, K. F. (1974) Seasonal adjustment and the relation between variables, Journal of the American Statistical Association, 69, 13-32. 


\section{Appendix 1.- The data}

Monthly seasonally unadjusted data from 1986:01 to 1998:04 are used for five countries: Germany (GM), Spain (SP), Japan (JP) United Kingdom (UK), and United States (US). The monetary aggregate, M2, is taken from EcoWin. The Industrial Production (IP) is used as a proxy for income, and is compiled from the OCDE. The exchange rates of the German mark (DEM), Japanese yen (JPY), Spanish peseta (ESP), and British pound (GBP) relative to the US dollar are taken from the OCDE.

Asset return data are generated by taking the first difference of the natural logarithm of the equity price index: DAX-XETRA (DAX) for GM, the General Index of the Madrid Stock Exchange (IGBM) is sufficiently representative of the Spanish stock exchange, the Nikkei-225 index (NIKKEI) is used for JP, the FT-100 (FT) for the UK, and Dow-Jones (DJ) for the US, (December 1994=100). Stock index data are taken from the Financial Times, London. Table 4 below reports time series analyses. Prior to the simulation, we start out by checking for the presence of extreme values. We performed intervention analysis (Box and Tiao, 1975). Time series analysis of the data indicates that these series do not display mean-reversion and hence they are a I(1) process. IP and M2 series show very regular seasonal patterns. The random walk process is consistent with the data generating process of the exchange rate and the stock index. All stock indexes show extreme values in the 1987 October crash. 
Appendix 2: Diagnostic analysis of GMM estimation: residual graphs, ACF and PACF.

Figure .1

GERMANY
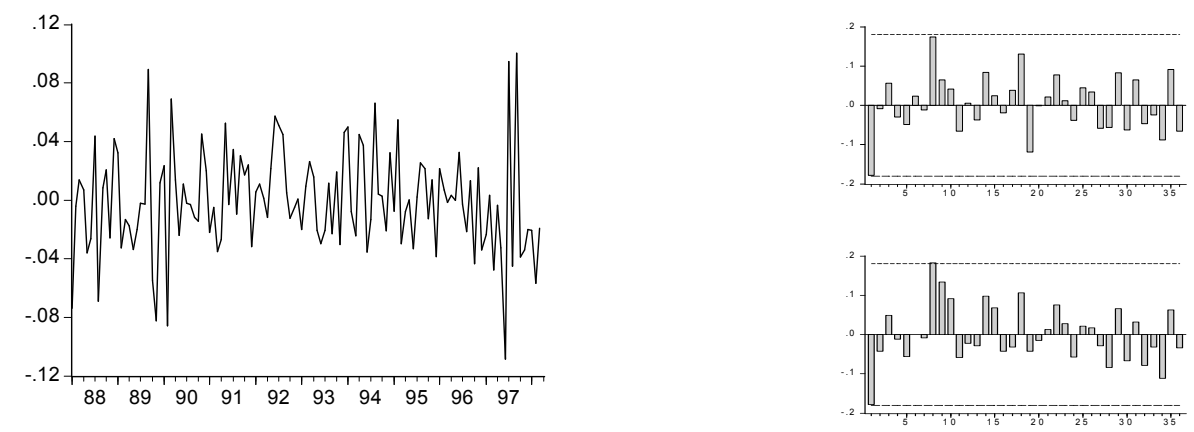

Figure 2

SPAIN
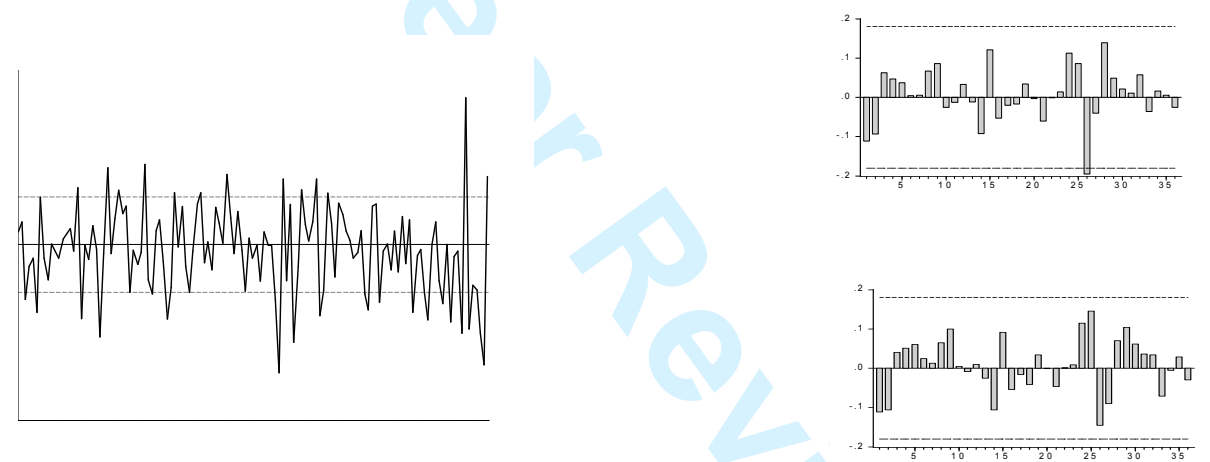

Figure 3

JAPAN
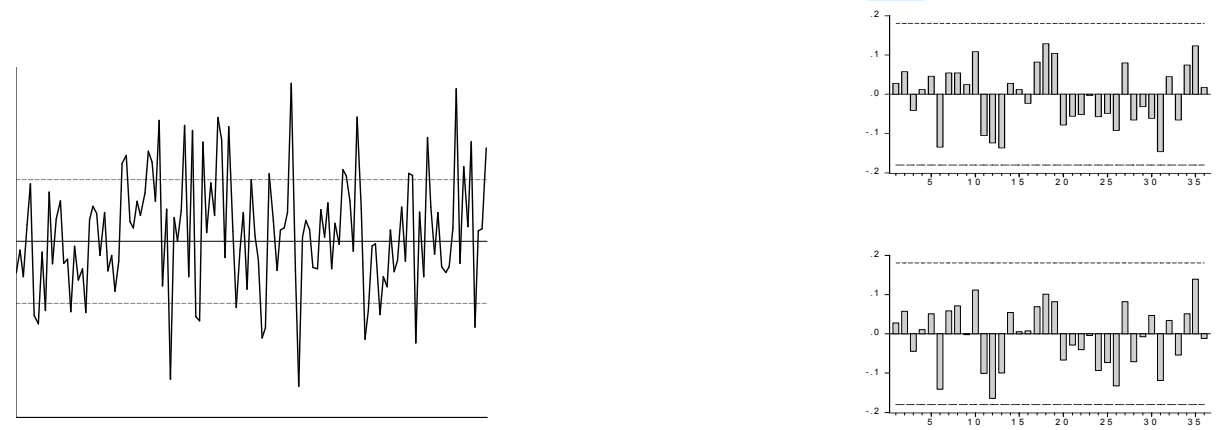
Figure 4

UNITED KINGDOM
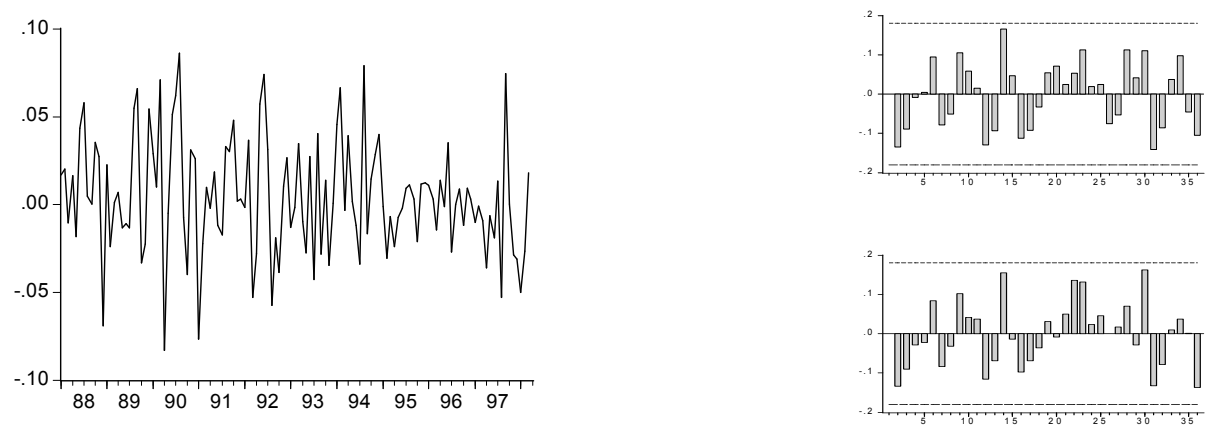

Figure 5

UNITED STATES
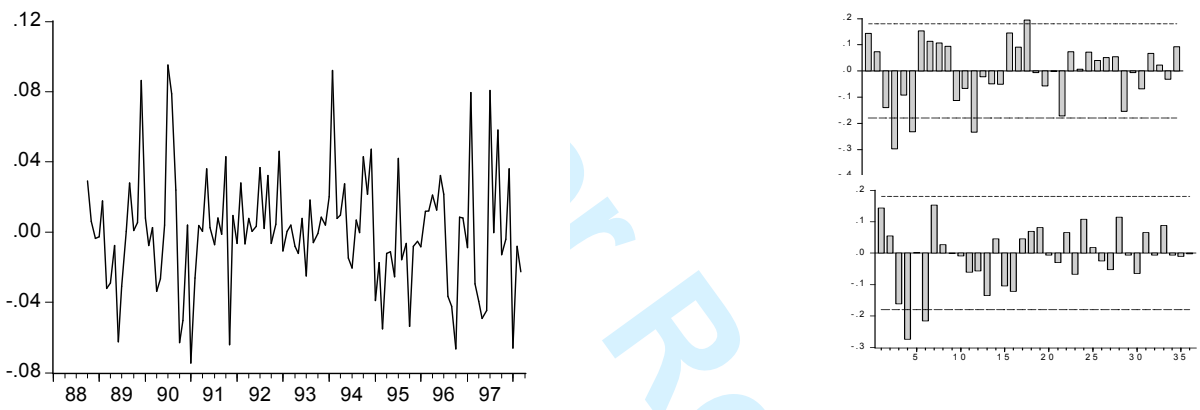


\section{Appendix 3: ObsExRa and ThtExRa}

Figure 6

Obs DEM / USD (Left) \& Tht DEM / USD (Right)
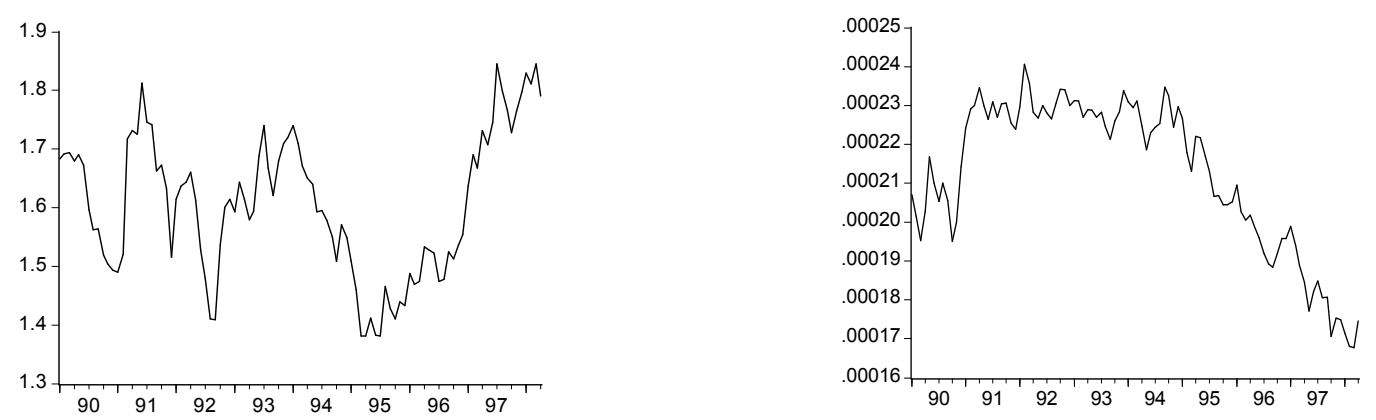

Figure 7

Obs GBP / USD (Left) \& Tht GBP / USD (Right)
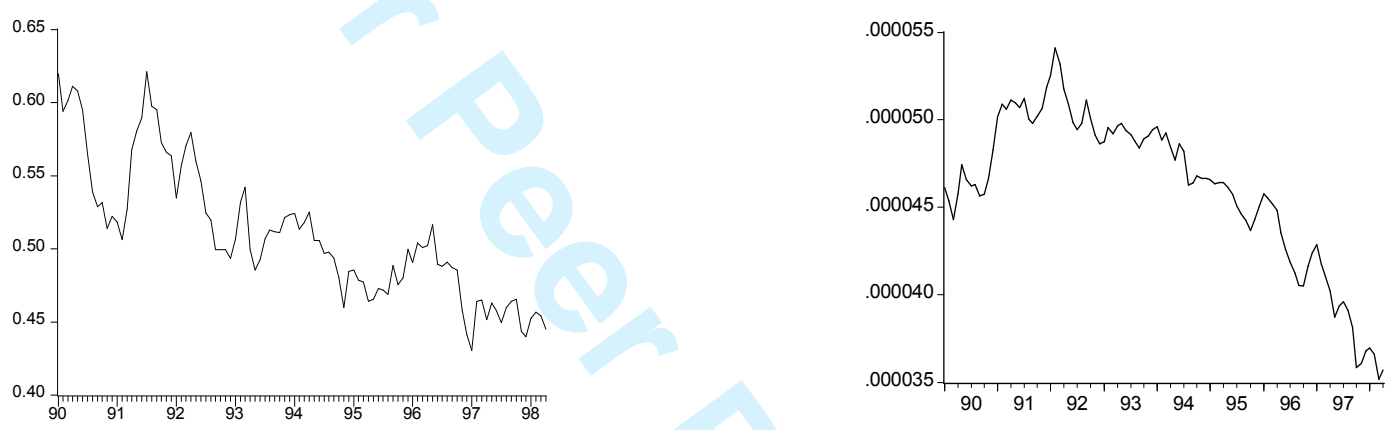

Figure 8

Obs ESP / USD (Left) \& Tht ESP / USD (Right)
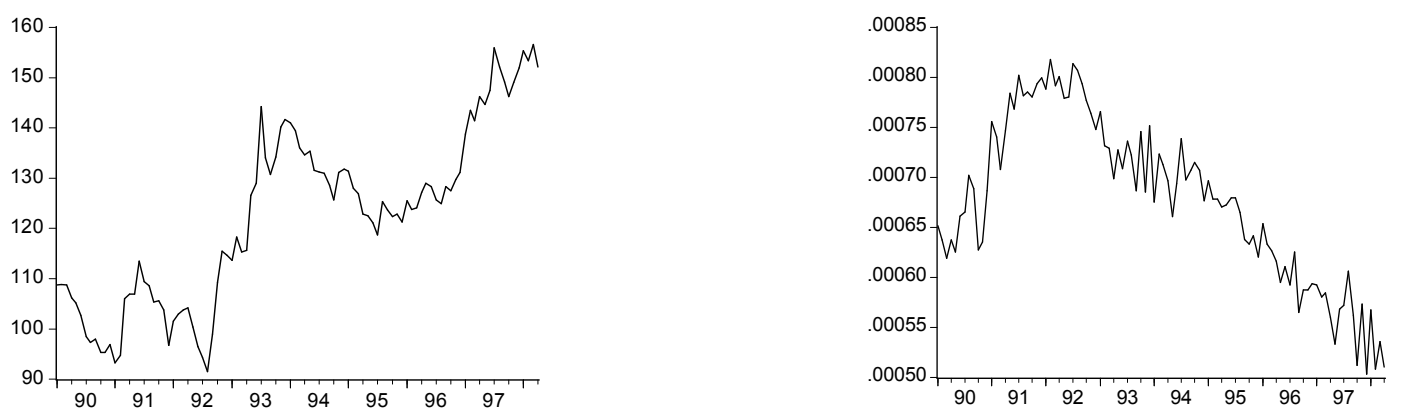
Figure 9

Obs JPY / USD (Left) \& Tht JPY / USD (Right)
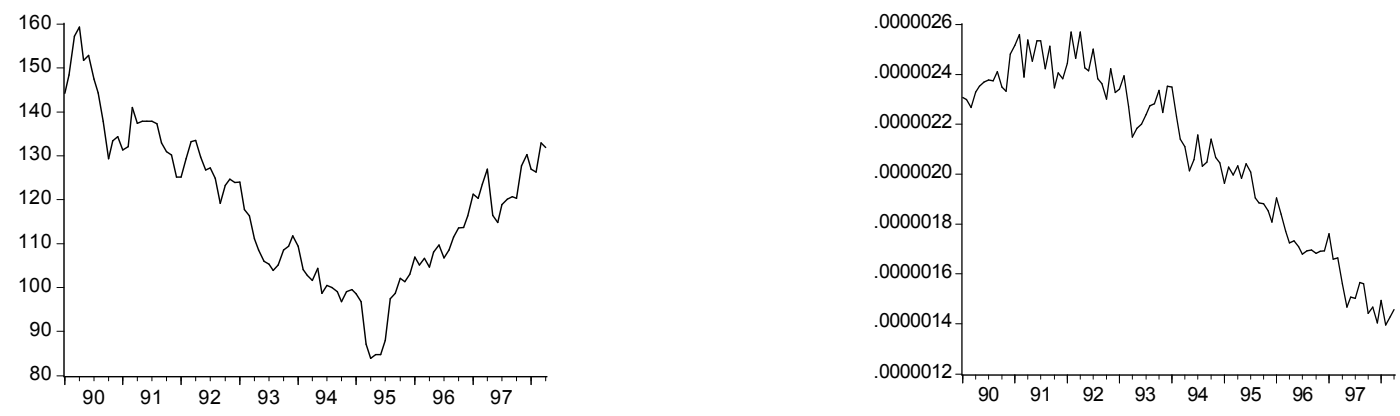

Figure 10

Obs GBP / DEM (Left) \& Tht GBP/ DEM (Right)
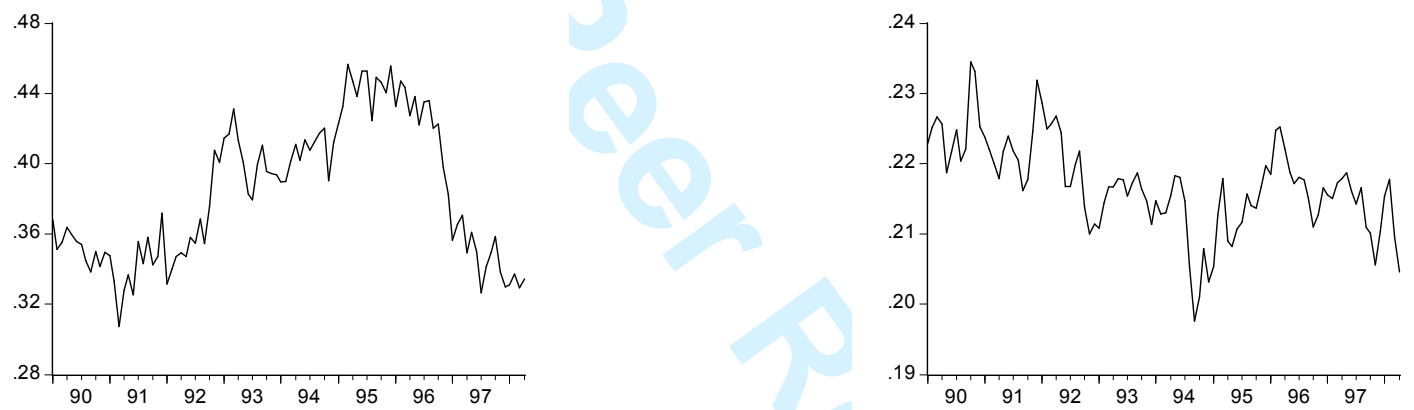

Figure 11

Obs ESP / DEM (Left) \& Tht ESP / DEM (Right)
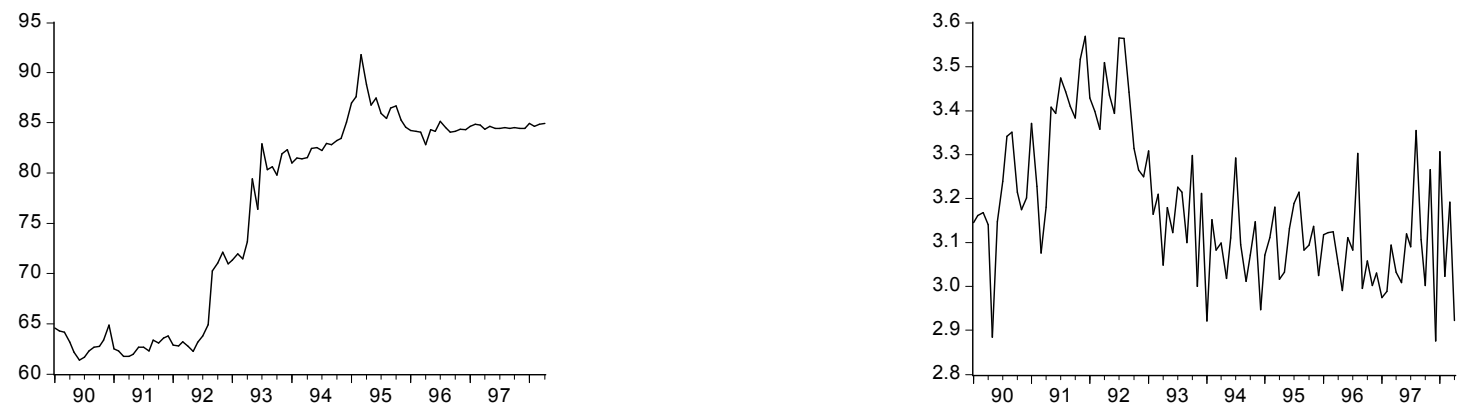


\section{Figure 12}

Obs JPY / DEM (Left) \& Tht JPY / DEM (Right)
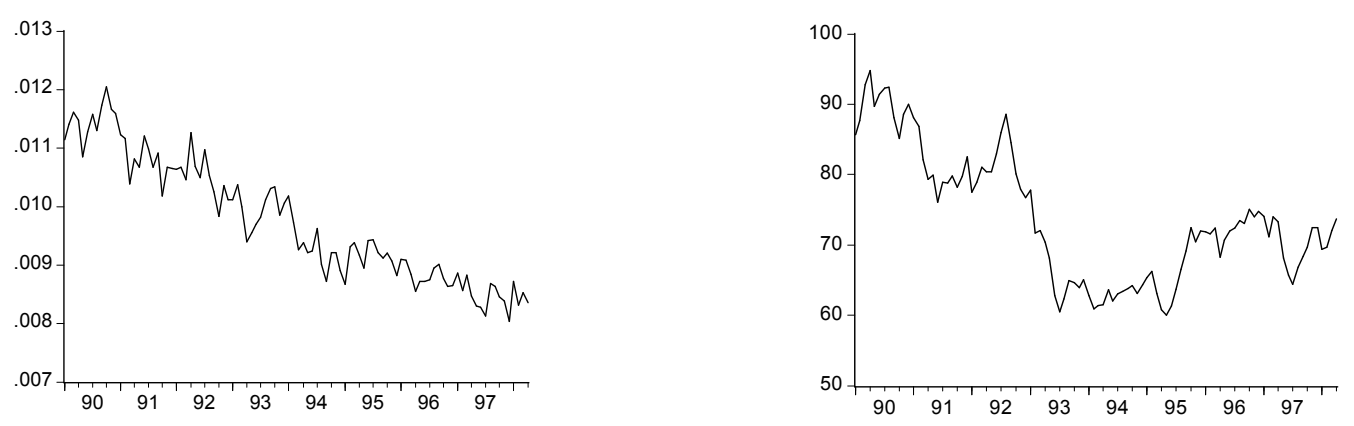


\title{
SEASONAL FLUCTUATIONS AND EQUILIBRIUM MODELS OF EXCHANGE RATE
}

\author{
Juan Ángel Jiménez Martín ${ }^{\text {a }}$ \\ Rafael Flores de Frutos ${ }^{\mathrm{b}}$ \\ ${ }^{a}$ Dpto. de Fundamentos de Análisis Económico II, Universidad Complutense. \\ ${ }^{\mathrm{b}}$ Dpto. de Fundamentos de Análisis Económico II, Universidad Complutense.
}

\begin{abstract}
Most of the evidence on dynamic equilibrium exchange rate models is based on seasonally adjusted consumption data. Equilibrium models have not worked well in explaining the actual exchange rate. However, the use of seasonally adjusted data might be responsible for the spurious rejection of the model. This paper presents a new equilibrium model for the exchange rates that incorporates seasonal preferences. The fit of the model to the data is evaluated for five industrialized countries using seasonally unadjusted data. Our findings indicate that a model with seasonal preferences can generate monthly time series of the exchange rate without seasonality even when the variables that theoretically determine the exchange rate show clear seasonal behaviours. Further, the model can generate theoretical exchange rates with the same order of integration than actual exchange rates, and in some cases, with the same stochastic trend.
\end{abstract}

JEL classification: F31, F37, G15

Keywords: exchange rate, equilibrium model, seasonality.

\footnotetext{
${ }^{*}$ Corresponding author. Dpto. de Fundamentos de Análisis Económico II, Universidad Complutense, Somosaguas, 28223, Spain. Tel.: +34 91394 2355. Fax: +34 91394 2613. E-mail: juanangel@ccee.ucm.es
} 


\title{
SEASONAL FLUCTUATIONS AND EQUILIBRIUM MODELS OF EXCHANGE RATE
}

\begin{abstract}
Most of the evidence on dynamic equilibrium exchange rate models is based on seasonally adjusted consumption data. Equilibrium models have not worked well in explaining the actual exchange rate. However, the use of seasonally adjusted data might be responsible for the spurious rejection of the model. This paper presents a new equilibrium model for the exchange rates that incorporates seasonal preferences. The fit of the model to the data is evaluated for five industrialized countries using seasonally unadjusted data. Our findings indicate that a model with seasonal preferences can generate monthly time series of the exchange rate without seasonality even when the variables that theoretically determine the exchange rate show clear seasonal behaviours. Further, the model can generate theoretical exchange rates with the same order of integration than actual exchange rates, and in some cases, with the same stochastic trend.
\end{abstract}

JEL classification: F31, F37, G15

Keywords: exchange rate, equilibrium model, seasonality. 


\section{1.- Introduction}

Equilibrium models state that the exchange rate is determined by macroeconomic fundamentals such as money supplies, prices, outputs, and interest rates. Several authors using different techniques have examined whether exchange rate can be forecast by these fundamentals: Kempa (2000) uses VAR methodology to identify the source of the real exchange rate volatility. Dravadakis (2005) uses a non-parametric cointegration setup; Moersch and Nautz (2001) and Tawadros (2001) estimate a structural monetary model of exchange rate; and MacDonald and Taylor $(1991,1994)$ and Moosa (1994) use linear cointegration techniques to test a reduced-form of the monetary model. Most of this empirical analysis on exchange rates has something in common, it is based on seasonally adjusted data. To our current knowledge, no previous studies have explored the idea of developing a model of exchange rate consistent with seasonality, a feature that is inherent in the fundamental variables determining the theoretical exchange rate, but absent of actual exchange rate time series.

Econometricians, rather than explicitly investigating the underlying economic seasonal variation, typically remove its effects by using seasonally adjusted data. Wallis (1974) shows that seasonal adjustment may distort the relations between variables. The effect of seasonal adjustment on asset pricing evidence has received only limited attention in the literature. Miron (1986) extended the seminal work of Hansen and Singleton (1982) to incorporate seasonal "taste shocks". Miron (1986) shows that when the seasonal fluctuations in consumption purchases are included in an analysis of the life cycle-permanent income model, there is no evidence in the aggregate data against the model. Ferson and Harvey (1992) examined consumption-based asset pricing models using seasonally unadjusted consumption data. They generalize the model of seasonality proposed by Miron (1986) studying models with "subsistence levels" in which the seasonal parameters are related to expected risk premium. They find that a model using not seasonally adjusted consumption data and nonseparable preferences with seasonal effects works better according to several criteria.

This paper proposes a model that generalizes standard dynamic equilibrium models of exchange rates by allowing for taste shocks like in Miron (1986). The key result is that this model can account for why exchange rates do not display seasonality even though the fundamental variables that theoretically explain them vary seasonally. Agents are acting to prevent exchange rates from fluctuating seasonally. The idea is: investors know that fundamental variables present seasonal variations, but their welfare improve if they smooth them over the entire year, thus avoiding the creation of intertemporal distortions when making their decision to invest.

An empirical estimation is then provided using seasonally unadjusted data for five major countries. First, we estimate the taste parameters of the agent preferences. For each exchange rate, then we generate theoretical time series. Stochastic properties of these time series 
are consistent with observed behaviour of exchange rates, i.e. (i) no seasonal fluctuations, and (ii) a degree of integration equal to 1 . Further, we wonder whether this model is able to generate exchange rates with the same long-run behaviour than their observed counterparts. We use cointegration analysis of the relationship between theoretical and observed exchange rates to ask this question. Here the presence of cointegration implies that the economic model can replicate the long-run evolution of the actual exchange rate, i.e. the theoretical exchange rate (or the current and expected futures values of observable economic fundamentals) contains useful information in forecasting the long-run behaviour of the observed exchange rate. Cointegration was found in some cases, but only in one case the cointegration vector presented the right sign, i.e. the model replicated the observed depreciation (appreciation) episodes only for the British pound / US dollar exchange rate.

The paper is organized as follows. Section 2 presents a two-country, two-goods cash-inadvance (CIA) model of the exchange rate that is a variation of the one developed in Grilli and Roubini (1992); in this section we describe a specific utility function with seasonal shocks. We evaluate our model in Section 3: First, we estimate the parameters applying the GMM estimator over stochastic Euler equations, second, we generate time series of the theoretical exchange rate for several currencies and third, we compare the stochastic properties of the theoretical and observed exchange rate. Concluding remarks appear in Section 4. Appendix 1 contains a description of the data. Appendix 2 shows the diagnostic analysis of GMM estimation. Appendix 3 presents time series data of observed and theoretical exchange rates.

\section{2.- The economy}

This section presents a CIA two-country economy that is subject to seasonal variation in preferences. A predecessor of this model is the work of Grilli and Roubini (1992), which analysed the open economy implications of models in which money is used both for transactions on goods markets and for transactions on asset markets. In this paper, however, in contrast to Grilli and Roubini, securities are traded instead of bonds and preferences with seasonal shocks are specified. First, we describe the economy and analyse the main implications of our model specifications for the equilibrium exchange rate. We then present the preferences, which are particularly important for the outcome of our analysis. Finally, the theoretical equilibrium exchange rate is obtained as an explicit function of fundamental variables and preference parameters.

\section{A.- The two-country exchange rate model}

There are two countries: Domestic (D) and Foreign (F). Each country has a firm that produces a perishable, traded, distinct good: $Y^{D}{ }_{b}, Y^{F}{ }_{t}$. Firms are assumed to be able to sell claims 
of their future random outputs. Domestic (foreign) claims entitle the owner to a proportionate share in the future stream of dividends.

There is one representative agent in each country. The representative agent from country $i$, for $i=D, F$, has preferences described by an infinite-horizon expected utility function given by:

$$
U_{t}=E_{t}\left[\sum_{l=t}^{\infty} \beta^{l-t} U\left(c_{i l}^{D}, c_{i l}^{F}\right)\right] \quad 0<\beta<1,
$$

where $E_{t}$ denotes the mathematical conditional expectation on information known at the beginning of period $t, \beta$ is a constant discount factor. Function $U$ is assumed to be bounded, continuously differentiable, increasing in both arguments, and strictly concave. $c_{i l}^{j}$, for $j=D, F$, is the good produced in country $j$ that is consumed by a resident of country $i$. Note that preferences are assumed to be identical across countries.

Residents of country $i$ are allowed to own shares in production in either country as well as the currency. The pattern of trading is assumed to proceed in a similar way to Lucas (1990). ${ }^{1}$ The transaction technology is that of the cash-in-advance model, extended by the assumption that the representative agent faces two liquidity constraints: one on the purchase of goods and one on the purchase of assets. Domestic (foreign) goods may be bought only with domestic (foreign) currency. Agents are thus subject to the following cash-in-advance constraints. Let $N_{i t}^{j}$ be the amount of money of country $j$ held by the representative agent of country $i$ for transactions in the goods market at time $t$, and let $P_{t}^{j}$ be the domestic and foreign currency prices for $\operatorname{good} j$. Then we require:

$$
\begin{aligned}
& N_{i t}^{D} \geq P_{t}^{D} c_{i t}^{D}, \quad i=D, F, \\
& N_{i t}^{F} \geq P_{t}^{F} c_{i t}^{F}, \quad i=D, F,
\end{aligned}
$$

Constraint (2) pertains to the currency of the domestic country, whereas (3) pertains to the currency of the foreign country. We now analyse equilibrium price determination. Equilibrium conditions for the currency for transactions on the goods markets are:

$$
N_{t}^{j}=N_{D t}^{j}+N_{F t}^{j}, \quad j=D, F
$$

Substituting (2)-(3) at equality in (4) gives:

$$
N_{t}^{j}=P_{t}^{j}\left(c_{D t}^{j}+c_{F t}^{j}\right), \quad j=D, F .
$$

Equilibrium in the goods markets requires:

$$
Y_{t}^{j}=c_{D t}^{j}+c_{F t}^{j}, \quad j=D, F .
$$

${ }^{1}$ There is a three-member representative household, each of whom goes his own way during a period, the three regrouping at the end of a day to pool goods, assets, and information: the owner of the firm collects the production; a second member of the household takes an amount of the household's initial cash balances and uses it to purchase goods from other households; and the third member carries out the remaining domestic and foreign currency cash balances on the securities and foreign exchange markets where domestic and foreign securities and currencies are sold and bought. 
Substituting (6) in (5) gives the quantitative theory equations:

$$
\begin{aligned}
& P_{t}^{D}=N_{t}^{D} / Y_{t}^{D} \\
& P_{t}^{F}=N_{t}^{F} / Y_{t}^{F}
\end{aligned}
$$

Therefore, the equilibrium prices of the two goods depend on domestic and foreign money supply.

In addition, there are two types of equities in this economy: domestic and foreign. These equities are traded on the securities market at a price (in units of domestic (foreign) currency) $Q^{D}{ }_{t}\left(Q_{t}^{F}\right)$. During the securities trading session, the agent has access to the foreign exchange market and can choose holdings of domestic and foreign securities. He/She therefore faces the budget constraints given by:

$$
\left[M_{i t}^{D}-N_{i t}^{D}\right]+S_{t}\left[M_{i t}^{F}-N_{i t}^{F}\right]=Q_{t}^{D} \omega_{i t}^{D}+S_{t} Q_{t}^{F} \omega_{i t}^{F}, \quad i=D, F,
$$

where $S_{t}$ is the nominal spot exchange rate expressed as the domestic price for foreign currency, $M_{i t}^{j}$ are $i$ holdings of money $j$ on date $t$, and $\omega_{i t}$ is the number of equities of country $j$ purchased at $t$ by a resident of country $i$.

In each period, the firm from country $j$ issues an amount of equities, the value of which has to be equal to its production. Thus:

$$
P_{t}^{j} Y_{t}^{j}=\left(\omega_{D, t}^{j}+\omega_{F, t}^{j}\right) Q_{t}^{j} \quad j=\mathrm{D}, \mathrm{F},
$$

At the beginning of period $t+1$, the ownership of equities entitles the owner to receive the dividend and to have the right to sell the equity at price $Q_{t+1}^{j}$. Dividends are random because they depend on production, which is assumed to be governed by an unspecified stochastic process. Therefore, the agent will begin $t+1$ with cash balances given by

$$
\begin{array}{ll}
M_{i t+1}^{D}=d_{t+1}^{D} \omega_{i t}^{D}+Q_{t+1}^{D} \omega_{i t}^{D} & i=D, F \\
M_{i t+1}^{F}=d_{t+1}^{F} \omega_{i t}^{F}+Q_{t+1}^{F} \omega_{i t}^{F} & i=D, F,
\end{array}
$$

where $\mathrm{d}_{\mathrm{t}}^{\mathrm{j}}$ are dividends per equity of firm $j(j=\mathrm{D}, \mathrm{F})$.

The domestic agent's optimisation problem may now be represented as follows. The agent chooses stochastic processes for $\left\{\mathrm{N}^{\mathrm{D}}{ }_{\mathrm{Dt}}, \mathrm{N}_{\mathrm{Dt}}^{\mathrm{F}}, \omega^{\mathrm{D}}{ }_{\mathrm{Dt}}, \omega^{\mathrm{F}}{ }_{\mathrm{Dt}}\right\}^{\propto}{ }_{\mathrm{t}=0}$ to maximize (1) subject to the cash-in-advance constraints (2)-(3), the budget constraint (8) and the transition equations for state variables (10)-(11). The agent's decision problem motivates the Bellman's equation,

$$
\mathrm{V}\left(\mathrm{M}_{\mathrm{Dt}}^{\mathrm{D}}, \mathrm{M}_{\mathrm{Dt}}^{\mathrm{F}}\right)=\operatorname{Max}_{\left\{\mathrm{N}_{D t}^{D}, \mathrm{~N}_{D t}^{F}, \omega_{D t}^{D}, \omega_{D t}^{F}\right\}}\left\{\mathrm{U}\left(\mathrm{N}_{D t}^{D} / \mathrm{P}_{t}^{D}, \mathrm{~N}_{D t}^{F} / \mathrm{P}_{t}^{F}\right)+\beta \mathrm{E}_{\mathrm{t}}\left(\mathrm{V}\left(\mathrm{M}_{\mathrm{Dt}+1}^{\mathrm{D}}, \mathrm{M}_{\mathrm{Dt}+1}^{\mathrm{F}}\right)\right)\right\}
$$

where $V\left(M_{D t}^{D}, M_{D t}^{F}\right)$ is the value function describing the maximized value of $U_{t}$ in (1). Since $U$ is concave and differentiable it follows that $V$ is concave and differentiable. ${ }^{2}$

${ }^{2}$ The attributes of the value function -existence, differentiability, and so on- are the subject of a vast technical literature. For main results and references, the interested reader should delve into Stockey and Lucas (1989). 
First order conditions associated with the problem stated in (12) are used to characterize equilibrium behaviour, given that the value function exists and is increasing, differentiable and concave:

$$
\begin{gathered}
V_{N_{D}^{\mathrm{D}}}\left(M_{D t}^{D}, M_{D t}^{F}\right)=U_{c_{D}^{D}}\left(c_{D t}^{D}, c_{D t}^{F}\right)\left(P_{t}^{D}\right)^{-1}=\lambda_{\mathrm{t}} \\
V_{\mathrm{N}_{D}^{F}}\left(M_{D t}^{D}, M_{D t}^{F}\right)=U_{c_{D}^{F}}\left(c_{D t}^{D}, c_{D t}^{F}\right)\left(P_{t}^{F}\right)^{-1}=\lambda_{\mathrm{t}} \mathrm{S}_{\mathrm{t}} \\
V_{\substack{\omega_{D}^{\mathrm{D}} \\
V_{\omega_{D}^{F}}}}\left(M_{D t}^{D}, M_{D t}^{F}\right)=\mathrm{Q}_{\mathrm{t}}^{\mathrm{D}} \lambda_{\mathrm{t}}=\beta \mathrm{E}_{t}\left[\mathrm{~V}_{\mathrm{M}_{D}^{D}}\left(M_{D t+1}^{D}, M_{D t+1}^{F}\right)\left(\mathrm{d}_{\mathrm{t}+1}^{\mathrm{D}}+\mathrm{Q}_{\mathrm{t}+1}^{\mathrm{D}}\right)\right] \\
\left.V_{D t}^{F}\right)=\mathrm{Q}_{\mathrm{t}}^{\mathrm{F}} \lambda_{\mathrm{t}} \mathrm{S}_{\mathrm{t}}=\beta \mathrm{E}_{t}\left[\mathrm{~V}_{\mathrm{M}_{\mathrm{D}}^{F}}\left(M_{D t+1}^{D}, M_{D t+1}^{F}\right)\left(\mathrm{d}_{\mathrm{t}+1}^{\mathrm{F}}+\mathrm{Q}_{\mathrm{t}+1}^{\mathrm{F}}\right)\right],
\end{gathered}
$$

where $\lambda_{t}$ is the multiplier associated with the budget constraint.

To transform these expressions into something more familiar we appeal to the envelope theorem. For an optimising agent, an increment to money on any date has the same effect on the lifetime utility regardless of the use to which the money is put, consumption or saving. An initial allocation in which, say, the marginal value of saving exceeds that of consumption can not be optimal. Agents could raise lifetime utility by reducing consumption a bit and saving more. The implication is that:

$$
\begin{aligned}
& \mathrm{V}_{\mathrm{M}_{\mathrm{D}}^{D}}\left(M_{D t+1}^{D}, M_{D t+1}^{F}\right)=U_{c_{D}^{D}}\left(c_{D t+1}^{D}, c_{D t+1}^{F}\right)\left(P_{t+1}^{D}\right)^{-1} \\
& \mathrm{~V}_{\mathrm{M}_{\mathrm{D}}^{F}}\left(M_{D t+1}^{D}, M_{D t+1}^{F}\right)=U_{c_{D}^{F}}\left(c_{D t+1}^{D}, c_{D t+1}^{F}\right)\left(P_{t+1}^{F}\right)^{-1}
\end{aligned}
$$

Substituting (13) and (17) in (15), the domestic firm equity price is given by:

$$
Q_{t}^{D}=\beta E_{t}\left(\frac{U_{c_{D}^{D}}\left(c_{D t+1}^{D}, c_{D t+1}^{F}\right)\left(P_{t+1}^{D}\right)^{-1}}{U_{c_{D}^{D}}\left(c_{D t}^{D}, c_{D t}^{F}\right)\left(P_{t}^{D}\right)^{-1}}\left(d_{t+1}^{D}+Q_{t+1}^{D}\right)\right)
$$

Symmetrically, substituting (14) and (18) in (16), the foreign firm equity price is given by:

$$
Q_{t}^{F}=\beta E_{t}\left(\frac{U_{c_{D}^{F}}\left(c_{D t+1}^{D}, c_{D t+1}^{F}\right)\left(P_{t+1}^{F}\right)^{-1}}{U_{c_{D}^{F}}\left(c_{D t}^{D}, c_{D t}^{F}\right)\left(P_{t}^{F}\right)^{-1}}\left(d_{t+1}^{F}+Q_{t+1}^{F}\right)\right)
$$

Finally, the solution for the equilibrium exchange rate is obtained from first order conditions (15)-(16), and envelope conditions (17)-(18):

$$
S_{t}=\frac{E_{t}\left[U_{c_{D}^{F}}\left(c_{D t+1}^{D}, c_{D t+1}^{F}\right)\left(P_{t+1}^{F}\right)^{-1}\left(d_{t+1}^{F}+Q_{t+1}^{F}\right)\left(Q_{t}^{F}\right)^{-1}\right]}{E_{t}\left[U_{c_{D}^{D}}\left(c_{D t+1}^{D}, c_{D t+1}^{F}\right)\left(P_{t+1}^{D}\right)^{-1}\left(d_{t+1}^{D}+Q_{t+1}^{D}\right)\left(Q_{t}^{D}\right)^{-1}\right]}
$$

If we compare (21) with the expression for the exchange rate in a typical cash-inadvance model, we notice that the crucial difference is represented by the ratio of returns from the investment on domestic and foreign equities. The intuition for the effect of this ratio on the equilibrium exchange rate is clear: part of the money supply is held for use in the asset market 
and thus does not enter in the determination of the goods prices. In particular, since goods prices depend on the money used in goods transactions, an increase in the returns expected from the investment on foreign equities, will increase the foreign money held for asset transaction, dropping the foreign money available for good market transactions. Consequently, this tends to reduce the foreign equilibrium prices of goods and thus depreciate the exchange rate.

To generate time series of theoretical exchange rate, it is necessary to characterize the agent preferences; in the next section, we present our assumption on these preferences.

\section{B- Seasonal shifts in preferences}

The issue of interest is that although the exchange rate is not seasonal, seasonal movements are a feature of many economic data series that theoretically determine the exchange rate, such as Gross Domestic Product (GDP), Industrial Product (IP), consumption, monetary aggregates, etc. The evidence suggests that optimising agents know that fundamental variables present seasonal variations and they smooth these when making an investment decision.

The question is: How can our equilibrium model explain this fact? In our model, expression (21) describing the solution for the equilibrium exchange rate can be written as:

$$
\mathrm{S}_{\mathrm{t}}=\frac{E_{t}\left(m_{t+1}^{F} R_{t+1}^{F}\right)}{E_{t}\left(m_{t+1}^{D} R_{t+1}^{D}\right)},
$$

where $m_{t+1}^{j}=U_{c_{D}^{j}}\left(c_{D t+1}^{D}, c_{D t+1}^{F}\right)\left(P_{t+1}^{j}\right)^{-1}$, for $j=D, F$, is the marginal utility gained from $\left(P_{t+1}^{j}\right)^{-1}$ units of commodity $c_{D t+l}^{j}$ consumed at $t+1$, and $R_{t+1}^{j}=\left(d_{t+1}^{j}+Q_{t+1}^{j}\right)\left(Q_{t}^{j}\right)^{-1}$ is the return on shares of country $j .{ }^{3}$ Therefore, the equilibrium exchange rate equalizes marginal utilities of currency across countries, when evaluated in a common currency. ${ }^{4}$

Since the exchange rate is not seasonal, we should not observe any seasonal variation on the marginal utility of the expected returns from the investment on shares. Note that $m_{t+l}$ is a function of consumption, and consumption usually possesses seasonality. Therefore, the seasonal pattern in consumption should be reflected in $R_{t+l}^{j}$ (however, the seasonal variation on asset returns, $R_{t+1}^{j}$ is minute compared with seasonal fluctuations in consumption) unless the

${ }^{3}$ The amount of commodity $c_{D t+1}^{j}$ that can be purchased with a unit of $j$ currency at time $t+1$ is the inverse of its price $\left(P^{j}{ }_{t+1}\right)^{-1}$. The utility from each one of these units of $c_{D t^{+1}}^{j}$ is given by its marginal utility, $U_{c_{D}^{j}}\left(c_{D t+1}^{D}, c_{D t+1}^{F}\right)$.

${ }^{4}$ For instance, for the UK pound / US dollar exchange rate case: the marginal utility expected from the investment of one pound on UK shares is $E_{t}\left(m^{D}{ }_{t+1} R^{D}{ }_{t+1}\right)$; the marginal utility expected from the investment of one pound on US shares is $E_{t}\left(m^{F}{ }_{t+1} R_{t+1}^{F}\right) / S_{t}$, that is, the US dollar value of a pound $\left(1 / S_{t}\right)$ multiplied by the marginal utility expected from the investment on US shares. 
agents remove seasonal fluctuations in consumption (for example, through function $U_{c_{D}^{j}}$ ) to a level that can be exactly mirrored in the real returns of all assets.

In our model, we conjecture that preferences that include seasonal shocks may counteract the seasonality in the fundamental variables. Therefore, we assume that the representative agents from both countries have identical preferences described by Miron, $(1986)^{5}$ :

$$
U\left(c_{i t}^{D}(s), c_{i t}^{F}(s)\right)=\frac{1}{1-\gamma^{D}}\left(c_{i t}^{D}(s)\right)^{1-\gamma^{D}}+\frac{1}{1-\gamma^{F}}\left(c_{i t}^{F}(s)\right)^{1-\gamma^{F}},
$$

where $c_{i t}^{j}(s)$ is the consumption service flow received in period $t$ by the agent from country $i$ for the consumption of the good produced in country $j$, in season $s$, and $\psi$ is the intertemporal elasticity of substitution in consumption of the consumption service of the good produced in country $j$. Consumers transform the stock of the consumption good produced in country $j, c_{i t}^{j}$, into consumption services according to the following function:

$$
\begin{aligned}
& c_{i t}^{j}(s)=\exp \left(\lambda^{j}{ }_{t}\right) c_{i t}^{j}, \quad j=D, F \\
& \lambda^{j}{ }_{t}=\theta_{1}^{\mathrm{j}} \mu_{t}(1)+\theta_{2}^{\mathrm{j}} \mu_{t}(2)+\ldots+\theta_{s}^{\mathrm{j}} \mu_{t}(s)
\end{aligned}
$$

where $\mu_{t}(s)$ is a dummy variable taking the value one when period $t$ corresponds to season $s$, and zero otherwise, and $\theta_{s}^{j}$ is the seasonal preference in season $s$. These parameters indicate that the utility obtained from $c_{i t}^{j}$ varies according to the prevailing season $s . c_{i t}^{j}(s)$ may thus be thought as the "seasonally adjusted" consumption.

\section{C.- Characterizing the equilibrium exchange rate}

In order to describe an equilibrium solution of the model, we require a distribution of wealth. We have assumed that wealth of every kind is evenly divided between the residents of the two countries. Specifically, the residents of each country own half of the domestic and foreign endowments, the stocks of domestic and foreign money and domestic and foreign assets. Given this distribution of wealth, consumption is given by: ${ }^{6}$

${ }^{5}$ We assume that the utility function is additively separable from the two consumption services and presents constant intertemporal substitution elasticity. Although this assumption is restrictive, it simplifies estimation considerably. Our analysis focuses on a simple basic utility function with seasonal shocks. We think this is valuable for setting a benchmark. Even so, the literature on equilibrium models of exchange rates includes heterogeneity of agents, multiple sectors, tax shocks, and modifications designed to reproduce features of exchange rates. Whether our findings are relevant for these cases is an open, quantitative issue that may be addressed using the procedures implemented in this paper.

6 This solution is the perfectly pooled equilibrium of Lucas (1982). Cole and Obstfeld (1991) show that the efficient allocations of resources in an economy like the one considered in this paper is of the form:

$$
c_{D t}^{D}=\theta_{1} Y_{t}^{D} \Rightarrow c_{F t}^{D}=\left(1-\theta_{1}\right) Y_{t}^{D} \text {, and } c_{D t}^{F}=\theta_{1} Y_{t}^{F} \Rightarrow c_{F t}^{F}=\left(1-\theta_{1}\right) Y_{t}^{F} .
$$




$$
\begin{array}{ll}
c_{i t}^{D}=Y_{t}^{D} / 2, & i=D, F \\
c_{i t}^{F}=Y_{t}^{F} / 2, & i=D, F .
\end{array}
$$

In addition, considering equilibrium prices given by (7) and the preferences defined above, (23)-(24), the equilibrium exchange rate given by expression (21) becomes:

$$
\mathrm{S}_{\mathrm{t}}=\frac{(1 / 2)^{-\gamma^{F}} E_{t}\left(\left(\exp \left[\sum_{\mathrm{s}=1}^{12} \theta_{S}^{F} \mu_{\mathrm{t}+1}(s)\right] \mathrm{Y}_{\mathrm{t}+1}^{\mathrm{F}}\right)^{1-\gamma^{F}}\left(\mathrm{~N}_{\mathrm{t}+1}^{\mathrm{F}}\right)^{-1} R_{t+1}^{F}\right)}{(1 / 2)^{-\gamma^{D}} E_{t}\left(\left(\exp \left[\sum_{\mathrm{s}=1}^{12} \theta_{S}^{D} \mu_{\mathrm{t}+1}(s)\right] \mathrm{Y}_{\mathrm{t}+1}^{D}\right)^{1-\gamma^{D}}\left(\mathrm{~N}_{\mathrm{t}+1}^{D}\right)^{-1} R_{t+1}^{D}\right)} .
$$

The intuition for this formula is straightforward: $m_{t+1}^{j}=2^{\gamma^{j}}\left(\exp \left[\sum_{\mathrm{s}=1}^{12} \theta_{S}^{j} \mu_{\mathrm{t}+1}(s)\right] \mathrm{Y}_{\mathrm{t}+1}^{j}\right)^{1-\gamma^{j}}\left(\mathrm{~N}_{\mathrm{t}+1}^{j}\right)^{-1}$, for $j=D, F$, is a function not only of money, goods endowments, but is also a function of the seasonal shifts in preferences. Evidence indicates that $Y_{t+1}^{j}$ and $N_{t+1}^{j}$ show seasonal patterns, however seasonal variation does not exist on $R_{t+1}^{j}$ and $S_{t}$. The introduction of seasonal parameters, $\theta_{S}$ (for $j=D, F$ and $S=1,2, \ldots, s$ ) allows the model to smooth the marginal utility of the expected returns from the investment on shares in the face of systematic seasonal fluctuations in $Y_{t+1}^{j}$ and $N_{t+1}^{j}{ }^{7}$

Now, we can consider the economic model to be an approximation to the stochastic processes generating the actual data. If the economic model is correctly specified, it could generate data with similar characteristics to those of the observed data. Expression (26) may be used to compute the exchange rate time series implied by this model and then compare it with real data. The next section describes the way to do this.

\section{Estimation of parameters and empirical evaluation of the seasonal model}

In this section, we evaluate our model analysing its capacity to generate time series of exchange rates with similar properties to observed exchange rates. We will use a procedure that consists of four steps:

It is simple to see that when these consumption expressions are assumed, proportionality factors in the consumption rules cancel out, leading exactly to the same expression (26). That means that, so long as countries are following efficient consumption allocations, the exchange rate will be determined by the same variables.

${ }^{7}$ To gain some intuition, let us focus on one season in which $Y_{t+1}^{j}$ is relatively low (if $\gamma^{j}>1$ ), then $m_{t+1}^{j}$ will be relatively high during this season, unless the seasonal parameter be relatively high to avoid seasonal fluctuations in the marginal utility of expected returns from investment. The taste shifts parameters indicate that the utility obtained from the consumption at time $t$ varies according the prevailing season $S$ and this explain that $m_{t+1}^{j}$ does not track seasonal patterns in $Y_{t+1}^{j}$ and $N_{t+1}^{j}$. Agents improve their welfare avoiding the creation of intertemporal distortions when making their decision to invest. 
(1) First, we estimate the preference parameters of the model exploiting orthogonality conditions from our model using Hansen's (1982) generalized method of moments (GMM). Theoretical variables are approximated by their observed counterparts. Outputs are approximated by monthly industrial production and monetary aggregates are approximated by M2. Asset returns are generated by taking a first difference on the natural logarithm of the equity price index.

(2) We then use expression (26) to generate theoretical exchange rate time series. The preference parameters are evaluated at their point estimates and the theoretical variables $Y_{t}, M_{t}$ and assets returns are approximated by their observed counterparts.

(3) We analyse the stochastic properties of theoretical exchange rates using Box-Jenkins methodology (Box and Jenkins, 1970).

(4) Finally, we study the presence of common trends between theoretical and observed exchange rates by using cointegration analysis.

\section{A. Details of the procedure for estimating preference parameters}

In this section, we briefly describe the estimation procedure. We focus on GMM estimation as implemented for dynamic rational expectations models by Hansen and Singleton (1982). The dynamic optimisation problem for an economic agent implies a set of stochastic Euler equations that must be satisfied in equilibrium. These Euler equations in turn imply a set of population orthogonality conditions that depend nonlinearly on variables observed by econometricians and on unknown parameters characterizing preferences. These conditions of orthogonality are used to construct a criterion function whose minimizer is the estimate of parameters.

Though there are many different types of Euler equations for the model specified in the previous section, the parameters are estimated by exploiting expression (19), which may also be written as:

$$
\beta E\left(\frac{U_{c_{D}^{j}}\left(c_{D, t+1}^{D}(s), c_{D, t+1}^{F}(s)\right)\left(P_{t+1}^{j}\right)^{-1}}{U_{c_{D}^{j}}\left(c_{D, t}^{D}(s), c_{D, t}^{F}(s)\right)\left(P_{t}^{j}\right)^{-1}}\left(d_{t+1}^{j}+Q_{t+1}^{j}\right)\left(Q_{t}^{j}\right)^{-1} \mid \mathrm{X}_{\mathrm{t}}\right)=1,
$$

where $X_{t}$ is a vector representing all the information available to the agent up to and including date $t^{8}$

${ }^{8}$ At date $t$, domestic and foreign agents know past and present stock prices and dividends, good prices, outputs, and money endowments: $X_{t}=\left\{Q_{t-l}^{j}, d_{t-l}^{j}, P_{t-l}^{j}, Y_{t-l}^{j}, M_{t-l}^{j}\right\}_{l=0}^{\infty}$ for $j=D, F$. All investors observe the same signals and thus share information set. To understand what this information set entails consider an economy that exists over time periods $t=1,2, \ldots$ Let $X_{t}$ denote the information set available to agents at date $t$. Let $h_{t}=\left\{N_{D t}^{D}, N^{F}{ }_{D t}, \omega^{D}{ }_{D t}\right.$, $\omega_{D t t^{2} t_{t=0}}$ denote a possible choice vector for an agent in period t. Let $X$ denote the collection of all possible agent information sets, and let $H$ denote the collection of all possible choice vectors. Then a sequence $\left(h_{l}, h_{2}, \ldots\right)$ of agent choice vectors is said to be chosen in accordance with a policy rule if there exists some well-defined function $g: X \rightarrow$ $H$ mapping information sets into choice vectors such that: $h_{t}=g\left(X_{t}\right), t=1,2, \ldots$. The solution to the domestic agent's 
Estimation using (27) requires the function $U$ to be explicitly parameterised. Therefore, when (23) is substituted in (27):

$$
E\left(\beta\left\{\exp \left(\sum_{\mathrm{s}=2}^{12} \theta_{\mathrm{s}}^{j}\left[\mu_{\mathrm{t}+1}(s)-\mu_{\mathrm{t}}(s)\right]\right)\right\}^{1-\gamma^{j}}\left(\frac{c_{D, t+1}^{j}}{c_{D, t}^{j}}\right)^{-\gamma^{j}}\left(\frac{P_{t}^{j}}{P_{t+1}^{j}}\right)\left(\frac{d_{t+1}^{j}+Q_{t+1}^{j}}{Q_{t}^{j}}\right)-1 \mid \mathrm{X}_{\mathrm{t}}\right)=0 .
$$

The nominal price of good $j$, for $j=D, F$, is given by cash-in-advance constraint (7) and assuming pooling equilibria as in (25), expression (28) becomes:

$$
E\left(\beta\left\{\exp \left(\sum_{s=2}^{12} \theta_{\mathrm{s}}^{j}\left[\mu_{\mathrm{t}+1}(s)-\mu_{\mathrm{t}}(s)\right]\right)\right\}^{1-\gamma^{j}}\left(\frac{Y_{t+1}^{j}}{Y_{t}^{j}}\right)^{-\gamma^{j}}\left(\frac{N_{t}^{j}}{N_{t+1}^{j}}\right)\left(\frac{d_{t+1}^{j}+Q_{t+1}^{j}}{Q_{t}^{j}}\right)-1 \mid \mathrm{X}_{\mathrm{t}}\right)=0 .
$$

Expression (29) requires the random variable described by:

$$
\beta\left\{\exp \left(\sum_{s=2}^{12} \theta_{\mathrm{s}}^{j}\left[\mu_{\mathrm{t}+1}(s)-\mu_{\mathrm{t}}(s)\right]\right)\right\}^{1-\gamma^{j}}\left(\frac{Y_{t+1}^{j}}{Y_{t}^{j}}\right)^{-\gamma^{j}}\left(\frac{N_{t}^{j}}{N_{t+1}^{j}}\right)\left(\frac{d_{t+1}^{j}+Q_{t+1}^{j}}{Q_{t}^{j}}\right)-1,
$$

to be uncorrelated with any variable contained in the information set $X_{t}$. It should therefore be the case that:

$$
E\left(\left[\beta\left\{\exp \left(\sum_{\mathrm{s}=2}^{12} \theta_{\mathrm{s}}^{j}\left[\mu_{\mathrm{t}+1}(s)-\mu_{\mathrm{t}}(s)\right]\right)\right\}^{1-\gamma^{j}}\left(\frac{Y_{t+1}^{j}}{Y_{t}^{j}}\right)^{-\gamma^{j}}\left(\frac{N_{t}^{j}}{N_{t+1}^{j}}\right)\left(\frac{d_{t+1}^{j}+Q_{t+1}^{j}}{Q_{t}^{j}}\right)-1\right] z_{t}\right]=0,
$$

where $z_{t}$ is any subset of the information set $X_{t}$ that we are able to observe.

Let $\psi_{o}^{j}=\left\{\beta, \gamma^{j}, \theta_{1}^{j}, \theta_{2}^{j}, \theta_{3}^{j}, \theta_{4}^{j}, \theta_{5}^{j}, \theta_{6}^{j}, \theta_{7}^{j}, \theta_{8}^{j}, \theta_{9}^{j}, \theta_{10}^{j}, \theta_{11}^{j}, \theta_{12}^{j}\right\} \in \mathfrak{R}^{14}$ denote the vector of unknown parameters, for $j=D, F$, that are to be estimated, and let $w_{t+1} \equiv\left(Y_{t+1}^{j}\left(Y_{t}^{j}\right)^{-1}, N_{t+1}^{j}\left(N_{t}^{j}\right)^{-1},\left(d_{t+1}^{j}+Q_{t+1}^{j}\right)\left(Q_{t}^{j}\right)^{-1},\left(\mu_{t+1}(s)-\mu_{t}(s)\right)\right)$ denote the vector of variables that are observed by agents for date $t+1$. Hence, we can define the function $h\left(w_{t+1}, \psi_{0}{ }^{j}\right)$ given by:

$$
h\left(w_{t+1}, \psi_{0}^{j}\right)=\beta\left\{\exp \left(\sum_{s=2}^{12} \theta_{\mathrm{s}}^{j}\left[\mu_{\mathrm{t}+1}(s)-\mu_{\mathrm{t}}(s)\right]\right)\right\}^{1-\gamma^{j}}\left(\frac{Y_{t+1}^{j}}{Y_{t}^{j}}\right)^{-\gamma^{j}}\left(\frac{N_{t}^{j}}{N_{t+1}^{j}}\right)\left(\frac{d_{t+1}^{j}+Q_{t+1}^{j}}{Q_{t}^{j}}\right)-1 .
$$

We can interpret (32) $\left(u_{t+1}=h\left(w_{t+1}, \psi_{0}^{j}\right)\right)^{9}$ as the disturbance vector in our econometric estimation, which should have finite second moments and, given (31),

optimization problem is a feasible policy rule $g^{*}: X \rightarrow H$ that determines how a particular policy vector $\mathrm{h}_{\mathrm{t}}$ should be chosen from $X$ on each period $t \geq 1$ given the dynamic state equations (10)-(11) that reveal how a choice of $h_{t}$ in period $t$ affects all current an future states of the economy.

${ }^{9}$ The utility function assumed in (23) is additively separable over time and additively separable in domestic and foreign goods. This assumption allows us to estimate seasonal taste parameters, factor discount and intertemporal elasticity of substitution parameters using single equation methods for each good. This can be seen by noting that in (32), $u_{t+1}$ is a function only of the variables $Y_{t}^{j}, M_{t}^{j}$ and asset returns corresponding to country $j(=\mathrm{D}, \mathrm{F})$. 


$$
E\left(u_{t+1} \mid \mathrm{X}_{\mathrm{t}}\right)=0
$$

We can now define the criterion function $f$ given by:

$$
f\left(w_{t+1}, z_{t}, \psi_{0}{ }^{j}\right)=h\left(w_{t+1}, \psi_{0}{ }^{j}\right) \otimes z_{t},
$$

where $z_{t}$ is the $q$ dimensional vector of variables with finite second moments that are in the agent's information set; and $f$ maps $R x R^{q} x R^{14}$ into $R^{q}$ and $\otimes$ is the Kronecker product. Thus, an implication of (33)-(34) and their accompanying assumptions is that

$$
E\left[f\left(w_{t+1}, z_{t}, \psi_{0}^{j}\right)\right]=0 .
$$

Equation (35) represents a set of $q$ population orthogonality conditions from which an estimator of $\psi_{0}{ }^{i}$ may be obtained, provided that $q$ is at least as large as the number of unknown parameters.

We proceed by constructing an objective function that depends only on available sample information and the unknown parameters. Let $g\left(\psi^{j}\right)=E\left[f\left(w_{t+1}, z_{t}, \psi^{j}\right)\right]$, where $\psi^{j} \in \mathfrak{R}^{14}$. Note that (35) implies that $g\left(\psi^{j}\right)$ has a zero at $\psi^{j}=\psi_{0}{ }^{j}$. Thus, the GMM estimator of $g\left(\psi^{j}\right)$

$$
g_{T}\left(\psi^{j}\right)=\frac{1}{T} \sum_{t=1}^{T} f\left(w_{t+1}, z_{t}, \psi^{j}\right)
$$

evaluated at $\psi^{j}=\psi_{0}{ }^{j}, g_{T}\left(\psi_{0}{ }^{j}\right)$, should be close to zero for large values of $T$. Given this fact, it is reasonable to select the $\psi^{j}$ that makes $g_{T}\left(\psi^{j}\right)$ “close" to zero. Therefore, a GMM estimator of $\psi_{0}{ }^{j}$ can be obtained by minimizing the quadratic form

$$
J_{T}\left[\psi^{j}\right]=\left[g_{T}\left(\psi^{j}\right)\right]^{\prime} W_{T}\left[g_{T}\left(\psi^{j}\right)\right],
$$

where $W_{T}$ is a $q$ by $q$ symmetric positive definite matrix that can depend on sample information. An important aspect of specifying a GMM problem is the choice of the weighting matrix. We use the optimal $W_{T}=\hat{\Omega}^{-1}$, where $\hat{\Omega}^{-1}$ is the estimated covariance matrix of the sample moments $q$.We use consistent Two-Stage least square estimates for the initial estimate of $\psi_{0}{ }^{j}$ in forming the estimate of $\Omega .^{10}$

\section{Estimation}

To estimate $\psi_{0}{ }^{j}$, we use monthly seasonally unadjusted data from 1986:01 to 1998:04 for five countries: Germany (GM), Spain (SP), Japan (JP), the United Kingdom (UK), and the United States (US). Outputs are approximated by the corresponding monthly industrial production (IP), monetary aggregates by the corresponding M2, and asset returns are generated

\footnotetext{
${ }^{10}$ We use Heteroskedasticity and an Autocorrelation Consistent Covariance Matrix of the sample moments.
} 
by taking a first difference on the natural logarithm of the equity price index. Appendix 1 describes the data and their stochastic properties. ${ }^{11}$

Table 1 shows the GMM estimation of $\psi_{0}^{j}$. The seasonal taste coefficients $\theta_{s}^{j}$, for $s=1$, $2,3, \ldots, 11$, and $j=G M, S P, J P, U K, U S$ indicate how the model seasonally adjusts consumption levels in month $s$ relative to December for the good produced in country $j$. December is chosen as a reference month $\left(\theta_{12}^{j}=1\right)$. Seasonal taste parameters are statistically significant in several cases: January, February, July, August, October, November for GM; in the case of SP all the seasonal parameters are statistically significant; January, February, March, May, August for JP; March, October and November for UK; and all the seasonal parameters are significant, except February, April and July, for US. The fact that seasonal preference shocks are significantly different from zero means that these shocks must be included in order to explain the joint behaviour of consumption and asset returns. The point estimates are intuitively plausible. We would expect values of $\theta_{s}^{j}>0$ for months with a low level of income relative to December to avoid seasonal fluctuations in the marginal utility of expected returns from investment. For instance, Spanish IP exhibits evident signs of seasonality, with a low value in December (reference month) and a deep trough in August. For Spain all seasonal preference parameters are negative, except $\theta_{8}^{S P}=0.344$, corresponding to August, which is a month of low working hours, due to holidays, and therefore low output.

The estimates of $\gamma^{j}$ are similar to those found in other studies, ranging from 0.74 to $2.42 .{ }^{12}$ In order to test the validity of overidentifying restrictions, Hansen's (1982) J-statistics are also displayed. The null hypothesis (overidentifying restrictions are satisfied) is not rejected at a $5 \%$ significance level in any case. ${ }^{13}$

(Insert Table 1)

Figures 1-5, in Appendix 2, show the residual graphs, autocorrelation function (ACF) and partial autocorrelation function (PACF) associated with GMM equations. Residuals are white noise.

${ }^{11}$ Hansen (1982) showed that sufficient conditions for the asymptotic properties of the GMM include strict stationarity of the data. Strict stationarity may be violated for some kinds of seasonal variation. However, consistency and asymptotic normality of the estimators and the asymptotic distribution of the test statistic can be demonstrated under weaker conditions. See Jagannathan (1983) and Lim (1985) for an analysis of the asymptotic properties of the GMM under seasonality and non-stationarity. Stationarity may also be violated under some models of growth rates of real outputs or monetary aggregates. In our empirical study, these growth rates are stationary.

12 Kydland and Prescott (1982) found that they needed a value of between one and two to mimic the observed relative variability of consumption and investment. Kehoe (1983), studying the response of small countries' balance of trade to terms of trade shocks, obtains estimates near one. Mehra and Prescott (1985) present evidence for restricting the value of relative risk aversion to a maximum of ten. Hansen and Singleton (1982) report values of $\gamma$ between zero and one. Mankiw (1985) reports values of between 2 and 4.

13 Note that preferences given by expressions (23) and (24) assume that seasonal taste coefficients vary across domestic and foreign goods. Risk aversion for each good is also different. So the finding of different $\theta_{s}^{j}$ and $\gamma^{j}$ for goods produced in different countries does not contradict the assumption of identical preferences. 


\section{B- Theoretical and observed exchange rates: Stochastic properties and} cointegration analysis

We restrict our testing strategy to the model implications in the statistical properties of the exchange rate. Once the entire parameters vector $\psi_{0}{ }^{j}$ is estimated, using the corresponding IP, M2 and the returns on assets, we generate several theoretical monthly time series implied by expression (26), evaluated at the point estimates of the utility function parameters of Table 1: German mark (DEM/USD) ${ }^{14}$, Japanese yen (JPY/USD), Spanish peseta (ESP/USD), and British pound (GBP/USD) relative to the US dollar, as well as Japanese yen (JPY/DEM), Spanish peseta (ESP/DEM), and British pound (GBP/DEM) relative to the German mark.

Table 2 reports a variety of descriptive statistics of the theoretical exchange rate, (ThtExRa) and the observed exchange rate (ObsExRa) over the sample period 1990:011998:04. ${ }^{15}$ Mean (M), standard deviation (Std) and the order of integration (d). The stochastic process of the ThtExRa time series is then analyzed and compared with the stochastic process characterizing the ObsExRa. Table 2 shows time series analysis results; diagnostic checks are developed to detect model inadequacy. Descriptive statistics to test for serial correlation in the residuals from estimated models are reported: Ljung-Box Q-statistics at lag $12(\mathrm{Q}(12))$.

\section{(Insert Table 2)}

The stochastic processes for all currencies (observed and theoretical) are modeled in first differences. Outliers in ObsExRa are analyzed to conclude that the random walk process is a valid representation for six out of the seven analyzed cases. The first difference in the GBP/DEM time series behaves as a first order autoregressive process.

Figures 6-12 in Appendix 3 plot monthly data for both theoretical and observed exchange rates, from 1990:01 to 1998:04. ${ }^{16}$

14

The currency is calculated as the value of the second country's currency. For example, (GBP/USD) is the number of British pounds needed to purchase a US dollar; in this case, the UK is the domestic country and the USA the foreign country.

${ }^{15}$ Equation (35), $E\left[f\left(w_{t+1}, z_{t}, \psi_{0}^{j}\right)\right]=0$, represents a set of population orthogonality conditions from which an estimator of the preference parameters $\left(\psi_{0}^{j}\right)$ may be obtained. Following Hansen and Singleton (1982), we use as instrumental variables $\left(z_{t}\right) p$ lags of the variables included in $w_{t+1} \equiv\left(Y_{t+1}^{j}\left(Y_{t}^{j}\right)^{-1}, N_{t+1}^{j}\left(N_{t}^{j}\right)^{-1},\left(d_{t+1}^{j}+Q_{t+1}^{j}\right)\left(Q_{t}^{j}\right)^{-1}\right.$, $\left.\left(\mu_{t+l}(s)-\mu_{t}(s)\right)\right)$. Therefore, parameter estimation is based only on $T-p$ observations. Because of the seasonal component of some of these variables - e.g., production growth rates, monetary aggregates growth rates-, long length (up to 48 months) of lagged values of $w_{t+1}$ are needed. In order to show a homogeneous sample analysis, the theoretical exchange rate simulation is started at date 1990:01.

${ }^{16}$ Empirical results do not show any increased ability of the model to explain exchange rate volatility. Volatility of the simulated exchange rate series is an order of magnitude smaller that the volatility of the actual exchange rate series. The analysis including non-traded goods or assuming market segmentation would increase the capacity of this model to replicate high volatility in the exchange rates, but to obtain closed-form solutions for the exchange rate and make the model amenable to intuition and empirical research, we assume that prices are flexible 
ThtExra is generated by expression (26) using seasonally unadjusted data (IP and M2). The time series analysis shows that autocorrelation of ThtExRa at the seasonal lags does not exist. Also, the forth column in Table 2 shows that ThtExRa time series follow integrated processes of order $1[\mathrm{I}(1)]$. Absence of seasonality and order of integration are two important features that ThtExRa and ObsExRa share, i.e. the theoretical model has successfully reproduced these two characteristics.

Now, we investigate whether observed and theoretical exchange rates share the same stochastic trend or long-run behaviour. Note that neither the parameter estimation procedure nor expression (26) that is used to generate the theoretical exchange rate take into account the observed exchange rates, therefore $O b s E x R a$ and ThtExRa might show very different long-run behaviours.

We perform a cointegration analysis between all pairs ThtExRa and ObsExRa time series. We use both the Augmented Engle and Granger (1987) procedure (AEG) and the more powerful Trace (Tr-ST) and Maximun eigenvalue (MaxAu-ST) tests developed by Johansen (1991,1992).

The existence of cointegration between theoretical and observed exchange rates implies that the economic model can replicate the long-run evolution of the actual exchange rate, i.e. it gives support to the hypothesis that exchange rates are determined (at least in the long-run) by current and expected futures values of economic fundamentals. If $O b s E x R a_{t}$ and $T h t E x R a_{t}$, are cointegrated then the cointegration relationship $\kappa_{t} \equiv O b s E x R a_{t}-\beta T h t E x R a_{t}$ is stationary with cointegrating vector $(1,-\beta)$. Further, a positive value for $\beta$ indicates that the economic model is able to replicate the appreciation or depreciation processes present in the observed exchange rate. Table 3 shows the results.

(Insert Table 3)

Test results support the model in the case of the GBP/USD exchange rate but do not support it for the remaining currencies: ${ }^{17}$

and PPP holds at every point. The paper must be viewed as a first attempt to incorporate seasonal preferences into a flexible price equilibrium model of exchange rate. While it may not have resolved all the equilibrium model problems, the development of more generalized preference structure allow us to replicate some stochastic properties of the actual exchange rate for some currencies: (1) no seasonal fluctuation and (2) degree of integration equal to one.

17 Both Engle and Granger and Johansen cointegration tests reject the null of no-cointegration between theoretical and observed variables for the same pair of exchange rates: GDP/USD and ESP/DEM. Later evidence is provided when error-correction models (ECM) are estimated for these two pairs of exchange rates. Augmented Dickey Fuller $t$ ratio test and $Z_{t}$ test suggested in Phillips (1987) (see Phillips and Ouliaris, 1990) failed to reject the null of no-cointegration for both pair of estimated cointegration vectors. The Lagrange multiplier statistic for firstorder serial correlation in residuals of the ECM shows that they do not suffer from serial correlation and the Lagrange multiplier statistic for first order autorregresive heteroskedasticity suggests that there is not evidence of 
1.- At the $10 \%$ critical value, the AEG test in Table 3 suggests that estimated cointegration relationship for the GBP/USD exchange rate is $\mathrm{I}(0)$. Johansen tests also provide evidence of cointegration at the $10 \%$ critical value. Additionally, as $\hat{\beta}$ is positive for this currency, the economic model also replicates the appreciation (or depreciation) observed in the actual time series. Figure 7 in Appendix 3 shows the ObsExRa and ThtExRa time series.

2.- The AEG and Johansen tests reported in Table 3 for the ESP/DEM exchange rate suggests, at the $10 \%$ significance level, that observed and theoretical time series appear to be cointegrated, but with $\hat{\beta}<0$; i.e. the economic model forecasts an appreciation when actual data shows depreciation and vice versa.

3.- For the remaining currencies, the tests reject cointegration at the $10 \%$ significance level. In these cases, although the economic model is able to replicate the absence of seasonality and order of integration in ObsExRa, it is not able to replicate its long-run behaviour.

\section{Conclusions}

Perhaps the most important characteristic of equilibrium models of the exchange rate is that they enable the discussion of evidence on the predictability of exchange rates from fundamental variables. Exchange rate equilibrium models illustrate how fundamental variables may affect the dynamics of the exchange rate. These models generate equilibrium pricing functions relating the exchange rate to real production, monetary aggregates an $\mathrm{d}$ asset returns. However, no previous studies have explored the idea of developing an equilibrium model of exchange rate consistent with the fact that while seasonality is inherent to the fundamental variables determining the exchange rate, it does not appear in the observed exchange rate.

This paper proposes a model that generalizes standard dynamic equilibrium models by allowing for seasonal shocks in preferences. In contrast with prior studies, the theoretical model is tested directly with seasonal unadjusted data. We found that the model with seasonal shocks in preferences explains how agents smooth seasonal movements in fundamental variables when they make their decisions to invest. Our model, for some currencies, is able to reproduce two important features of the stochastic process generating the actual exchange rate: (1) the absence of seasonal fluctuations and (2) the degree of integration equal to one. Further, in the case of the GBP/USD rate, the model also captures the long-term patterns as well as the appreciation and depreciation episodes found in the data.

The results in this paper provide a certain counterbalance to the bleak view in relation to the usefulness of equilibrium models of exchange rate determination. We have focused on a

autorregresive conditional heteroskedasticity. Normality of residuals is tested by the Jarque-Bera statistic. We only found deviations from normality in the residuals of the ECM associated with the observed ESP/DEM exchange rate. This long-tailed distribution is explained by two outliers detected in 10/92 and 5/93 due to the European Monetary System crisis. However, an intervention analysis reveals that cointegration tests were not distorted 
simple, basic equilibrium exchange rate model, but we believe this to be a modest contribution by setting a benchmark. 


\section{Acknowledgements}

We thank the editor, one referee, A Novales, L. Puch, J. Ruiz and T. Sinclair for their helpful comments. We have benefited from comments from seminar participants at the Unit Root and Cointegration Testing Conference. We would like to acknowledge the financial support of the Ministerio de Educación, Spain, through Project BEC2003-03965 and the Fundacion Caja Madrid. Parts of this work were completed while J. A. Jimenez-Martin was a visitor at the George Washington University, Washington, DC. The authors are grateful to this institution for its hospitality.

\section{References}

Box, G.E.P. and Jenkins, G. M. (1970) Time Series Analysis, Forecasting and Control, ed. Holden-Day, San Francisco.

Box, G. E. P. and Tiao, G. C. (1975) Intervention analysis with applications to economic and environmental problems, Journal of American Statistical Association, 70, 70-79.

Cole, H. and Obstfeld, M. (1991) Commodity trade and international risk sharing: how much do financial markets matter? Journal of Monetary Economics, 28, 3-24.

Davidson, R. and MacKinnon, J.G. (1993), Estimation and Inference in Econometrics, Oxford University Press, New York.

Davradakis, E. (2005) Macroeconomic fundamentals and exchange rates: a non-parametric cointegration analysis, Applied Financial Economics, 15, 439-446.

Engle, R. and Granger, C. (1987) Co-integration and error correction: representation, estimation, and testing, Econometrica, 55, 251-276.

Grilli, V. and Roubini, N. (1992) Liquidity and exchange rates, Journal of International Economics, 33, 339-352.

Ferson, W. E. and Harvey, C. (1992) Seasonality and consumption-based asset pricing, The Journal of Finance, 47, 511-552.

Hansen, L. (1982) Large sample properties of generalized method of moments estimators, Econometrica, 50, 1029-1084.

Hansen, L. P. and Singleton, K. J. (1982) Generalized instrumental variables estimation of nonlinear rational expectations models, Econometrica, 50 (5), 1269-1286.

Jagannathan, R. (1983) Three essays on the pricing of derivative claims, Doctoral Dissertation, Carnegie Mellon University.

Johansen, S. (1991) Estimation and hypothesis testing of cointegrating vectors in gaussian vector autoregressive models, Econometrica, 59, 1551-80.

Johansen, S. (1992) Statistical analysis of cointegrated vectors, Journal of Economic Dynamics and Control, 12, 231-54, June-September.

Kehoe, T. (1983) Dynamics of the current account: theoretical and empirical analysis, Working Paper, Harvard University, Cambridge, MA. 
Kempa, B. (2000), Excess volatility of real exchange rates in the EMS: some evidence from structural VARs, 32, Applied Economics, 73-79.

Kydland, F. E. and Prescott, E. C. (1982) Time to build and aggregate fluctuations, Econometrica, 50, 1345-1370.

Lim, K. G. (1985) Estimating and testing rational expectations models under non-stationarity, Doctoral Dissertation, Stanford University.

Lucas, R. E. Jr. (1990) Liquidity and interest rates, Journal of Economic Theory, 50, 237-264

Lucas, R. E. Jr. (1982) Interest rates and currency prices in a two-country world, Journal of Monetary Economics, 10, 335-359.

Lucas, R. E. Jr. (1978) Asset prices in an exchange economy, Econometrica, 46, 1429-45.

Mankiw, N. G. (1985) Consumer durables and the real interest rate, Review of Economics and Statistic, 67, 353-362.

McDonald, R. and Taylor, M. P. (1991) The monetary approach to the exchange rate, Economics Letters, 37, 179-85.

McDonald, R. and Taylor, M. P. (1994) The monetary model of the exchange rate: long-run relationships, short run dynamics and how to beat a random walk, Journal of International Money and Finance, 13, 276-90.

Mehra, R. and Prescott, E. C. (1985) The equity premium: a puzzle, Journal of Monetary Economics, 15, 145-161.

Miron, A. J. (1986) Seasonal fluctuations and the life cycle-permanent income model of consumption, Journal of Political Economy, 94, 1258-1279.

Moersch, M. and D. Nautz. (2001), A note on testing the monetary model of the exchange rate, Applied Financial Economic, 11, 261-268.

Moosa, I. A. (1994) The monetary model of the exchange rate revisited, Applied Financial Economics, 26, 279-287.

Osterwald-Lenum, M. (1992) A note with quantiles of the asymptotic distribution of the maximum likelihood cointegration rank test statistics, Oxford Bulletin of Economics and Statistics, 54, 461-472.

Phillips, P. and Ouliaris, S. (1990) Asymptotic Properties of Residual Based Tests for Cointegration, Econometrica, 58, 165-193.

Phillips, P. (1987), Time series regression with a unit root, Econometrica, 55, 277-301.

Stockey, N. and Lucas, R. E. (1989) Recursive Methods in Economic Dynamics, Harvard University Press, Massachusetts.

Tawadros, G. B. (2001) The predictive power of the monetary model of exchange rate determination, Applied Financial Economics, 11, 279-286.

Wallis, K. F. (1974) Seasonal adjustment and the relation between variables, Journal of the American Statistical Association, 69, 13-32. 
Tables

Table 1: GMM estimation of utility function parameters ${ }^{(a)}$

\begin{tabular}{|c|c|c|c|c|c|c|c|c|c|c|c|c|c|}
\hline & $\theta_{1}^{(\mathrm{c})(\mathrm{d})}$ & $\theta_{2}$ & $\theta_{3}$ & $\theta_{4}$ & $\theta_{5}$ & $\theta_{6}$ & $\theta_{7}$ & $\theta_{8}$ & $\theta_{9}$ & $\theta_{10}$ & $\theta_{11}$ & $\gamma$ & J_Sta ${ }^{(\mathrm{e})(\mathrm{f})}$ \\
\hline$\theta_{s}^{\mathrm{GM}(\mathrm{b})}$ & $\begin{array}{l}0.130^{*} \\
(0.06)\end{array}$ & $\begin{array}{l}0.121^{* *} \\
(0.07)\end{array}$ & $\begin{array}{r}0.033 \\
(0.08)\end{array}$ & $\begin{array}{l}0.112 \\
(0.09)\end{array}$ & $\begin{array}{l}0.125 \\
(0.08)\end{array}$ & $\begin{array}{l}0.079 \\
(0.08)\end{array}$ & $\begin{array}{l}0.156^{* *} \\
(0.09)\end{array}$ & $\begin{array}{l}0.270 * \\
(0.12)\end{array}$ & $\begin{array}{l}0.066 \\
(0.09)\end{array}$ & $\begin{array}{l}-0.061^{*} \\
(0.09)\end{array}$ & $\begin{array}{l}*-0.022 * \\
(0.05)\end{array}$ & $\begin{array}{l}1.31^{*} \\
(0.18)\end{array}$ & $\begin{array}{l}29.52 \\
(0.10)\end{array}$ \\
\hline$\theta_{s}^{\mathrm{SP}}$ & $\begin{array}{l}-0.115^{*} \\
(0.03)\end{array}$ & $\begin{array}{l}-0.153^{*} \\
(0.05)\end{array}$ & $\begin{array}{l}-0.255^{*} \\
(0.06)\end{array}$ & $\begin{array}{l}-0.262 * \\
(0.08)\end{array}$ & $\begin{array}{l}-0.349^{*} \\
(0.10)\end{array}$ & $\begin{array}{l}-0.328^{*} \\
(0.09)\end{array}$ & $\begin{array}{l}-0.264 * \\
(0.08)\end{array}$ & $\begin{array}{l}0.344^{*} \\
(0.06)\end{array}$ & $\begin{array}{l}-0.106^{* *} \\
(0.05)\end{array}$ & $\begin{array}{l}-0.133 * \\
(0.05)\end{array}$ & $\begin{array}{l}*-0.139 * \\
(0.04)\end{array}$ & $\begin{array}{l}0.74 * \\
(0.08)\end{array}$ & $\begin{array}{l}27.06 \\
(0.76)\end{array}$ \\
\hline$v_{s}$ & $\begin{array}{l}0.139 * \\
(0.03)\end{array}$ & $\begin{array}{l}0.107 * \\
(0.05)\end{array}$ & $\begin{array}{l}-0.038^{*} \\
(0.03)\end{array}$ & $\begin{array}{l}0.090 \\
(0.03)\end{array}$ & $\begin{array}{l}0.154 * \\
(0.07)\end{array}$ & $\begin{array}{l}0.019 \\
(0.04)\end{array}$ & $\begin{array}{l}0.032 \\
(0.05)\end{array}$ & $\begin{array}{l}0.137 * \\
(0.05)\end{array}$ & $\begin{array}{l}0.012 \\
(0.05)\end{array}$ & $\begin{array}{l}0.003 \\
(0.04)\end{array}$ & $\begin{array}{l}-0.005 \\
(0.02)\end{array}$ & $\begin{array}{l}1.51^{*} \\
(0.41)\end{array}$ & $\begin{array}{l}18.45 \\
(0.68)\end{array}$ \\
\hline & $\begin{array}{l}0.047 \\
(0.05)\end{array}$ & $\begin{array}{l}0.012 \\
(0.06)\end{array}$ & $\begin{array}{l}-0.182 * \\
(0.06)\end{array}$ & $\begin{array}{l}-0.063 \\
(0.06)\end{array}$ & $\begin{array}{l}-0.112 \\
(0.08)\end{array}$ & $\begin{array}{l}-0.151 \\
(0.09)\end{array}$ & $\begin{array}{l}-0.003 \\
(0.07)\end{array}$ & $\begin{array}{l}0.096 \\
(0.06)\end{array}$ & $\begin{array}{l}-0.053 \\
(0.06)\end{array}$ & $\begin{array}{l}-0.118^{*} \\
(0.05)\end{array}$ & $\begin{array}{c}*-0.106 * \\
(0.03)\end{array}$ & $\begin{array}{l}1.22 * \\
(0.11)\end{array}$ & $\begin{array}{l}20.97 \\
(0.52)\end{array}$ \\
\hline$\theta_{\mathrm{s}}^{\text {US }}$ & $\begin{array}{l}0.022 * \\
(0.004)\end{array}$ & $\begin{array}{l}0.001 \\
(0.004)\end{array}$ & $\begin{array}{l}-0.007^{*} \\
(0.003)\end{array}$ & $\begin{array}{l}-0.002 \\
(0.004)\end{array}$ & $\begin{array}{l}0.017 * \\
(0.005)\end{array}$ & $\begin{array}{c}-0.034 * \\
(0.004)\end{array}$ & $\begin{array}{l}0.001 \\
(0.005)\end{array}$ & $\begin{array}{l}-0.031 * \\
(0.004)\end{array}$ & $\begin{array}{l}-0.042^{*} \\
(0.003)\end{array}$ & $\begin{array}{l}-0.037^{*} \\
(0.003)\end{array}$ & $\begin{array}{l}*-0.014 * \\
(0.001)\end{array}$ & $\begin{array}{l}2.42^{*} \\
(0.036)\end{array}$ & $\begin{array}{l}25.83 \\
(0.81)\end{array}$ \\
\hline
\end{tabular}

(a) The instruments are: a constant term, lagged production growth rates, lagged monetary aggregates growth rates, and lagged rates of return.

(b) Germany (GM), Spain (SP), Japan (JP), United Kingdom (UK), United States (US)

(c) Estimated standard errors in brackets

(d) Statistical significance is indicated by a single asterisk $(*)$ for the $5 \%$ level, and a double asterisk $(* *)$ for the $10 \%$ level

(e) J-statistic, for testing the validity of overidentifying restrictions. Under the null hypothesis, the overidentifying restrictions are satisfied, the J-statistic (i.e. the minimized value of the objective function) times the number of observations is asymptotically $\chi_{\mathrm{q}}^{2}$, with degrees of freedom equal to the number of overidentifying restrictions

(f) P values represented in brackets.

Table 2: Summary of ARIMA ${ }^{18}$ models fitted to the ThtExRa and the ObsExRa

\begin{tabular}{|c|c|c|c|c|c|}
\hline & $\bar{M}$ & Std. & $\nabla^{\mathrm{d}}$ & $\mathrm{Q}(12)$ & ARIMA MODELS $^{(\mathrm{a})(\mathrm{b})}$ \\
\hline$O b s$ DEM/USD & $1.6 * 10^{0}$ & $1.2 * 10^{-1}$ & $\nabla$ & 9.7 & $\mathrm{Y}_{\mathrm{t}}=0.20 \xi_{\mathrm{t}}^{\mathrm{S} 3 / 91}+\mathrm{N}_{\mathrm{t}} \quad \nabla \mathrm{N}_{\mathrm{t}}=\mathrm{a}_{\mathrm{t}}$ \\
\hline Tht DEM/USD & $2.1 * 10^{-4}$ & $1.9 * 10^{-5}$ & $\nabla$ & 12.6 & $\begin{array}{l}\left(1-0.16 B+0.32 B^{2}\right) \nabla Y_{t}=a_{t} \\
(0.10)(0.10)\end{array}$ \\
\hline Obs ESP/USD & $1.2 * 10^{2}$ & $1.6 * 10$ & $\nabla$ & 0.9 & $\begin{aligned} & \mathrm{Y}_{\mathrm{t}}=(7.5+10.2 \mathrm{~B}) \xi_{\mathrm{t}}^{\mathrm{S} 9 / 92}+12.7 \xi_{\mathrm{t}}^{\mathrm{I7/93}}+\mathrm{N}_{\mathrm{t}} \quad \nabla \mathrm{N}_{\mathrm{t}}=\mathrm{a}_{\mathrm{t}} \\
&(3.5)(3.5)\end{aligned}$ \\
\hline Tht $\mathrm{ESP} / \mathrm{USD}$ & $6.8 * 10^{-4}$ & $8.1 * 10^{-5}$ & $\nabla$ & 18.4 & $\begin{array}{c}\left(1+0.52 \mathrm{~B}+0.15 \mathrm{~B}^{2}+0.23 \mathrm{~B}^{4}\right) \nabla \mathrm{Y}_{\mathrm{t}}=\mathrm{a}_{\mathrm{t}} \\
(0.10)(0.11) \quad(0.10)\end{array}$ \\
\hline Obs GBP/USD & $6.1 * 10^{-1}$ & $4.6 * 10^{-2}$ & $\nabla$ & 6.6 & $\begin{aligned} Y_{t}= & (0.08+0.08 B) \xi_{t}^{S 1092}+N_{t} \\
& (0.02)(0.02)\end{aligned}$ \\
\hline Tht GBP/USD & $4.6 * 10^{-5}$ & $4.4 * 10^{-6}$ & $\nabla$ & 10.9 & $\begin{array}{l}\left(1-0.37 \mathrm{~B}+0.25 \mathrm{~B}^{2}+0.18 \mathrm{~B}^{4}\right) \nabla \mathrm{Y}_{\mathrm{t}}=\mathrm{a}_{\mathrm{t}} \\
(0.10)(0.10) \quad(0.10)\end{array}$ \\
\hline Obs JPY/USD & $1.2 * 10^{2}$ & $1.7 * 10$ & $\nabla$ & 22.4 & $\mathrm{Y}_{\mathrm{t}}=-10.5 \xi_{\mathrm{t}}^{\mathrm{S5} / 97}+\mathrm{N}_{\mathrm{t}}$ \\
\hline Tht JPY/USD & $2.1 * 10^{-6}$ & $3.5 * 10^{-7}$ & $\nabla$ & 18.7 & $\begin{array}{l}(1+0.35 \mathrm{~B}) \nabla \mathrm{Y}_{\mathrm{t}}=\mathrm{a}_{\mathrm{t}} \\
\quad(0.09)\end{array}$ \\
\hline$O b s$ ESP/DEM & $7.6 * 10$ & $1.0 * 10$ & $\nabla$ & 12.6 & $\begin{array}{c}\mathrm{Y}_{\mathrm{t}}=5.37 \xi_{\mathrm{t}}^{\mathrm{S} 9 / 92}+\left(6.26-3.0 \mathrm{~B}+6.45 \mathrm{~B}^{2}\right) \xi_{\mathrm{t}}^{\mathrm{S} / 93}+3.59 \xi_{\mathrm{t}}^{13 / 95}+\mathrm{N}_{\mathrm{t}} \\
\quad(0.83) \\
\nabla \mathrm{N}_{\mathrm{t}}=\mathrm{a}_{\mathrm{t}}\end{array}$ \\
\hline Tht $\mathrm{ESP} / \mathrm{DEM}$ & $0.3 * 10$ & $1.6 * 10^{-1}$ & $\nabla$ & 14.5 & $\begin{array}{l}\left(1+0.64 \mathrm{~B}+0.27 \mathrm{~B}^{2}+0.29 \mathrm{~B}^{3}\right) \nabla \mathrm{Y}_{\mathrm{t}}=\mathrm{a}_{\mathrm{t}} \\
(0.10)(0.11) \quad(0.10)\end{array}$ \\
\hline Obs GBP/DEM & $3.8^{*} 10^{-1}$ & $4.0 * 10^{-2}$ & $\nabla$ & 6.55 & $\begin{array}{l}(1+0.25 \mathrm{~B}) \nabla \mathrm{Y}_{\mathrm{t}}=\mathrm{a}_{\mathrm{t}} \\
(0.09)\end{array}$ \\
\hline Tht GBP/DEM & $2.2 * 10^{-1}$ & $6.6 * 10^{-3}$ & $\nabla$ & 10 & $\begin{array}{l}\left(1-0.21 \mathrm{~B}+0.41 \mathrm{~B}^{2}\right) \nabla \mathrm{Y}_{\mathrm{t}}=\mathrm{a}_{\mathrm{t}} \\
(0.10)(0.10)\end{array}$ \\
\hline Obs JPY/DEM & $7.4 * 10$ & $0.9 * 10$ & $\nabla$ & 8.5 & $\nabla \mathrm{Y}_{\mathrm{t}}=\mathrm{a}_{\mathrm{t}}$ \\
\hline Tht JPY/DEM & $9.7 * 10^{-3}$ & $1.0 * 10^{-3}$ & $\nabla$ & 17.3 & $\begin{array}{l}\left(1+0.34 \mathrm{~B}+0.22 \mathrm{~B}^{2}\right) \nabla \mathrm{Y}_{\mathrm{t}}=\mathrm{a}_{\mathrm{t}} \\
(0.10)(0.11) \quad(0.10)\end{array}$ \\
\hline
\end{tabular}

(a) Estimated standard errors in brackets

(b) $\xi_{t}^{I " T "}=\left\{\begin{array}{ll}1 & t=T \\ 0 & t \neq T\end{array} ; \quad \xi_{t} S^{\prime \prime} T^{\prime \prime}=\left\{\begin{array}{ll}1 & t \geq T \\ 0 & t<T\end{array} ;\right.\right.$

${ }^{18}$ Autoregressive Integrated Moving Average (ARIMA) Model 
Table 3. Testing for cointegration between $O b s E x R a$ and ThtExRa.

\begin{tabular}{|c|c|c|c|c|c|c|c|c|c|}
\hline \multirow[b]{2}{*}{ ExRa } & \multicolumn{4}{|c|}{ AEG } & \multicolumn{2}{|c|}{$\mathrm{Tr}_{\mathrm{CS}} \mathrm{ST}^{(\mathrm{c})}$} & \multicolumn{2}{|c|}{ MaxAu_ST } & \multirow[b]{2}{*}{ Lag } \\
\hline & $\beta_{0}^{(a)(b)}$ & $\beta_{1}$ & $\tau_{\mu}$ & Lag & $\mathrm{H}_{0}: \mathrm{r}=0$ & $\mathrm{H}_{0}: \mathrm{r} \leq 1$ & $\mathrm{H}_{0}: \mathrm{r}=0$ & $\mathrm{H}_{0}: \mathrm{r} \leq 1$ & \\
\hline DEM/USD & $\begin{array}{l}0.2 * 10 \\
(0.1 * 10)\end{array}$ & $\begin{array}{l}-1.5^{*} 10^{3} \\
\left(0.6^{*} 10^{3}\right)\end{array}$ & -2.54 & 1 & 7.60 & 0.74 & 6.87 & 0.74 & 2 \\
\hline ESP/USD & $\begin{array}{l}17 * 10^{2} \\
(0.8 * 10)\end{array}$ & $\begin{array}{l}-9.3 * 10^{4} \\
\left(1.1 * 10^{4}\right)\end{array}$ & -2.32 & 5 & 7.62 & 1.25 & 6.36 & 1.25 & 1 \\
\hline GBP/USD & $\begin{array}{l}2.0^{2} 10^{-1} \\
\left(0.4 * 10^{-1}\right)\end{array}$ & $\begin{array}{l}6.6^{*} 10^{3} \\
\left(0.8^{*} 10^{3}\right)\end{array}$ & $-3.26^{* *}$ & 0 & $15.66^{* *}$ & 2.53 & $12.83^{* *}$ & 2.53 & 1 \\
\hline JPY/USD & $\begin{array}{l}8.4 * 10 \\
(1.0 * 10)\end{array}$ & $\begin{array}{l}1.6^{*} 10^{7} \\
\left(0.5^{*} 10^{7}\right)\end{array}$ & -1.21 & 0 & 6.56 & 2.44 & 4.13 & 2.44 & 1 \\
\hline ESP/DEM & $\begin{array}{l}2.0^{*} 10^{2} \\
\left(0.2 * 10^{2}\right)\end{array}$ & $\begin{array}{l}-3.9 * 10 \\
(0.5 * 10)\end{array}$ & $-3.23^{* *}$ & 10 & $29.35^{*}$ & 3.91 & $25.45^{*}$ & 3.90 & 1 \\
\hline GBP/DEM & $\begin{array}{l}8.4 * 10^{-1} \\
\left(1.2 * 10^{-1}\right)\end{array}$ & $\begin{array}{l}-0.2 * 10 \\
(0.6 * 10)\end{array}$ & -1.79 & 0 & 8.41 & 1.80 & 6.62 & 1.80 & 2 \\
\hline JPY/DEM & $\begin{array}{l}1.3 * 10 \\
(0.6 * 10)\end{array}$ & $\begin{array}{l}6.3 * 10^{3} \\
\left(0.6^{*} 10^{3}\right)\end{array}$ & -2.80 & 1 & 9.59 & 1.70 & 7.89 & 1.70 & 2 \\
\hline
\end{tabular}

(a) The AEG test is related to the Engle-Granger (EG) test (Engle and Granger, 1987), in the same way as the ADF test is related to the ordinary DF. The EG test involves first using OLS to estimate the following cointegration regression:

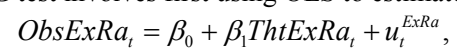

and then using an ordinary Dickey Fuller test based on the regression:

$$
\nabla u_{t}^{E x R a}=\mu+(1-\alpha) u_{t}^{E x R a}+\varepsilon_{t} .
$$

Since serial correlation may be a problem, AEG test uses the ADF test instead of the DF test testing for unit roots on $\mathrm{u}_{\mathrm{t}}^{E x R a}$. If $\mathrm{u}_{\mathrm{t}}^{\text {ExR }}$ is $\mathrm{I}(0)$, regression (38) implies that the variables ObsExRa and ThtExRa will be cointegrated with the cointegrating vector $\left(1,-\beta_{1}\right) . \tau_{\mu}$ is computed in exactly the same way as the ordinary $t$ statistic for $\alpha-1=0$ in regression (39). The lag length ( $\mathrm{Lag}$ ) of the lagged difference terms of the dependent variable on the right hand side of (39) is determined using the Akaike information criterion (AIC). Maximum number of lag $=12$. Critical values for the AEG test are taken from Davidson and MacKinnon (1993). -3.90 (1\%), -3.34 (5\%), -3.04 (10\%). Statistical significance is indicated by a single asterisk (*) for the $5 \%$ level, and a double asterisk $(* *)$ for the $10 \%$ level.

(b) Estimated standard errors in brackets.

(c) The system variables are (ObsExRa and ThtExRa). The lag value indicates the order of the vector error correction model (VECM) estimated for each currency, which is determined using the Akaike information criterion (AIC). The asymptotic critical values (without a constant in the data generating process, although the cointegrating equations have intercepts) obtained from Osterwald-Lenum (1992) are presented in the following table, in which $\mathrm{p}$ is the number of system variables and $h$ is the number of cointegration relations under the null hypothesis. $\operatorname{Tr} z$ are the critical values for Johansen's likelihood ratio test of the null hypothesis of $h$ cointegration relations against the alternative of $N O$ restrictions. Max are the critical values for Johansen's likelihood ratio test of the null hypothesis of $h$ cointegration relations against the alternative of $h+1$ relations. Statistical significance is indicated by a single asterisk $(*)$ for the $5 \%$

\begin{tabular}{|c|c|c|c|c|}
\hline \multicolumn{5}{|c|}{ Asymptotic critical values } \\
\hline & $\mathrm{p}-\mathrm{h}$ & $1 \%$ & $5 \%$ & $10 \%$ \\
\hline \multirow[b]{2}{*}{ Trz } & 1 & 11.57 & 8.08 & 6.69 \\
\hline & 2 & 21.96 & 17.84 & 15.58 \\
\hline \multirow{2}{*}{ Max } & 1 & 11.58 & 8.08 & 6.69 \\
\hline & 2 & 18.78 & 14.59 & 12.78 \\
\hline
\end{tabular}
level, and a double asterisk $(* *)$ for the $10 \%$ level. 


\section{Appendix 1.- The data}

Monthly seasonally unadjusted data from 1986:01 to 1998:04 are used for five countries: Germany (GM), Spain (SP), Japan (JP) United Kingdom (UK), and United States (US). The monetary aggregate, M2, is taken from EcoWin. The Industrial Production (IP) is used as a proxy for income, and is compiled from the OECD. The exchange rates of the German mark (DEM), Japanese yen (JPY), Spanish peseta (ESP), and British pound (GBP) relative to the US dollar are taken from the OECD.

Asset return data are generated by taking the first difference of the natural logarithm of the equity price index: DAX-XETRA (DAX) for GM, the General Index of the Madrid Stock Exchange (IGBM) is sufficiently representative of the Spanish stock exchange, the Nikkei-225 index (NIKKEI) is used for JP, the FT-100 (FT) for the UK, and Dow-Jones (DJ) for the US, (December 1994=100). Stock index data are taken from the Financial Times, London. Prior to the simulation, we start out by checking for the presence of extreme values. We performed intervention analysis (Box and Tiao, 1975). Time series analysis of the data indicates that these series do not display mean-reversion and hence they are integrated processes of order 1. IP and M2 series show very regular seasonal patterns. The random walk process is consistent with the data generating process of the exchange rate and the stock index. All stock indexes show extreme values in the 1987 October crash. 
Appendix 2: Diagnostic analysis of GMM estimation: residual graphs, ACF and PACF.

Figure .1

GERMANY
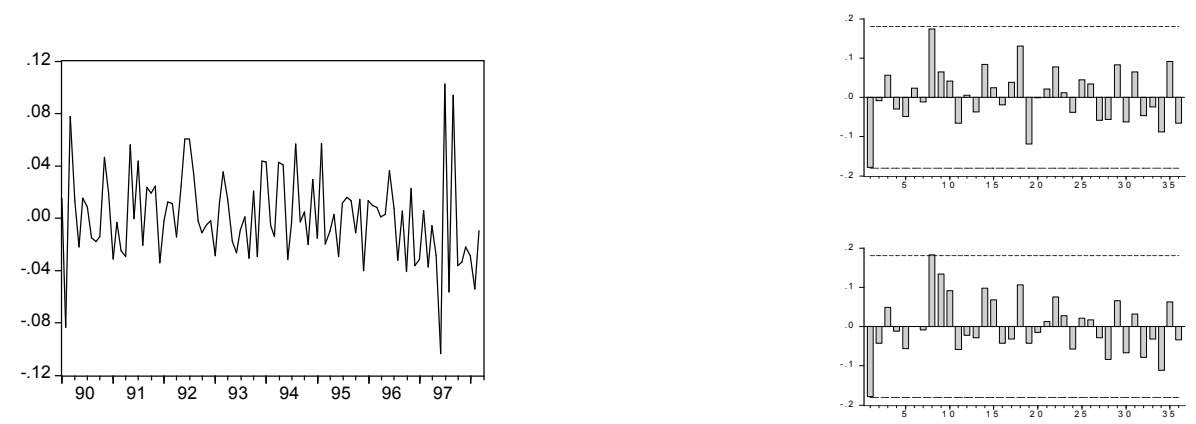

Figure 2

SPAIN
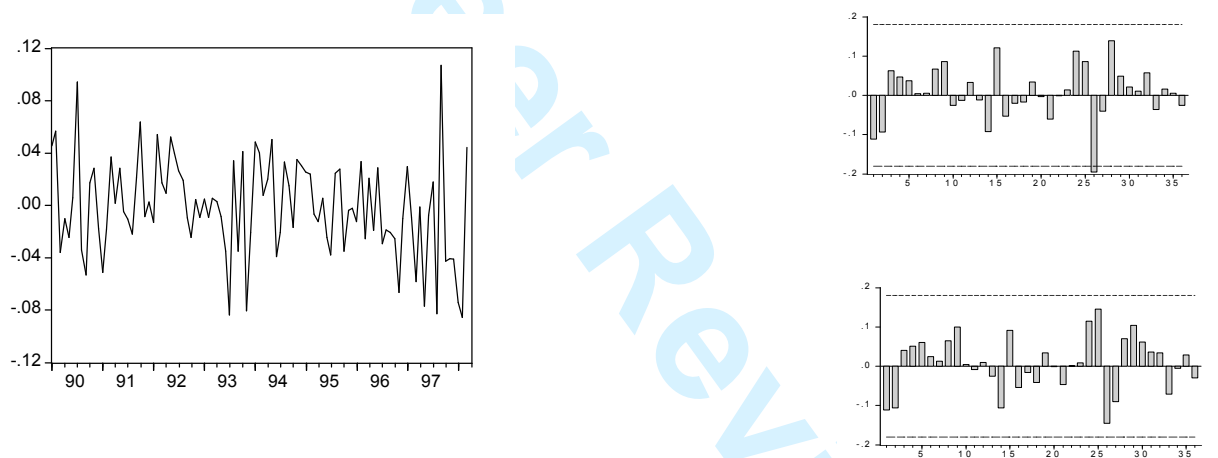

Figure 3

JAPAN
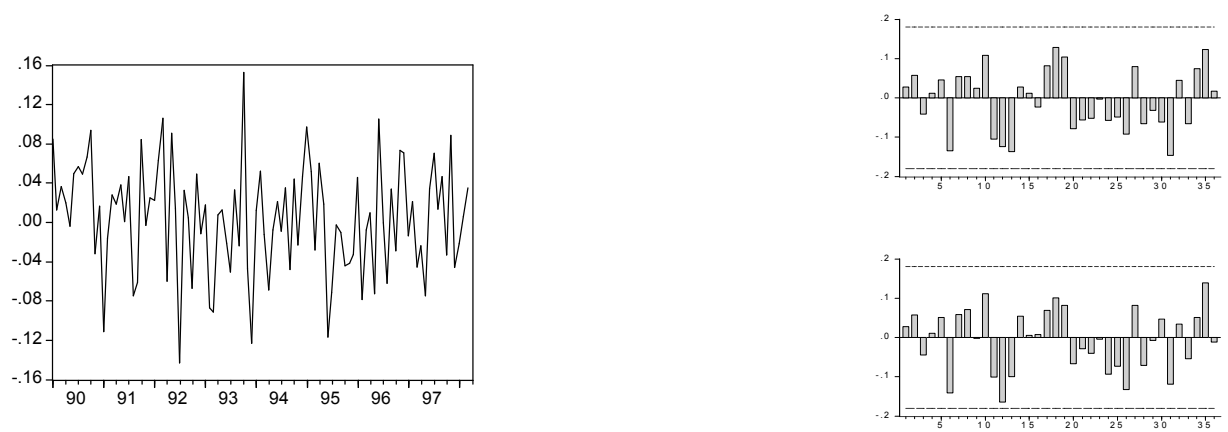
Figure 4

UNITED KINGDOM
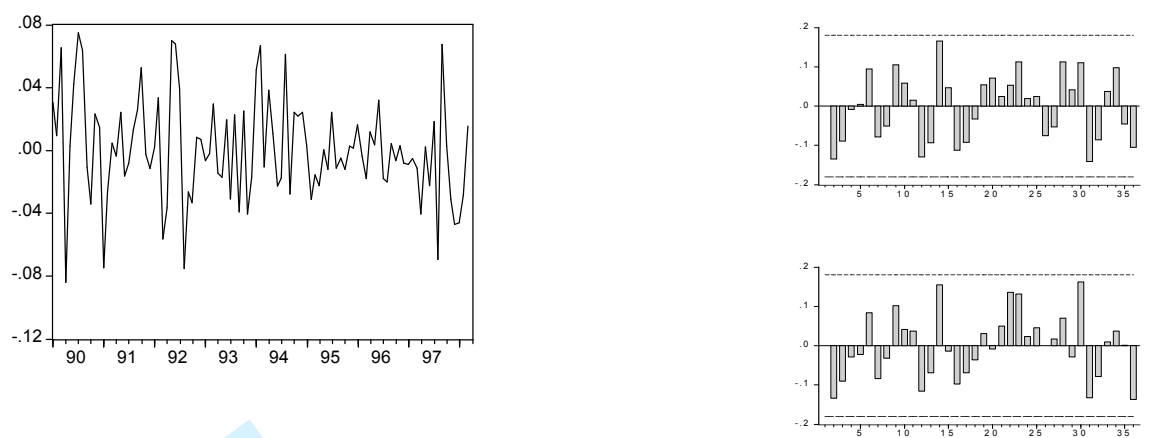

Figure 5

UNITED STATES
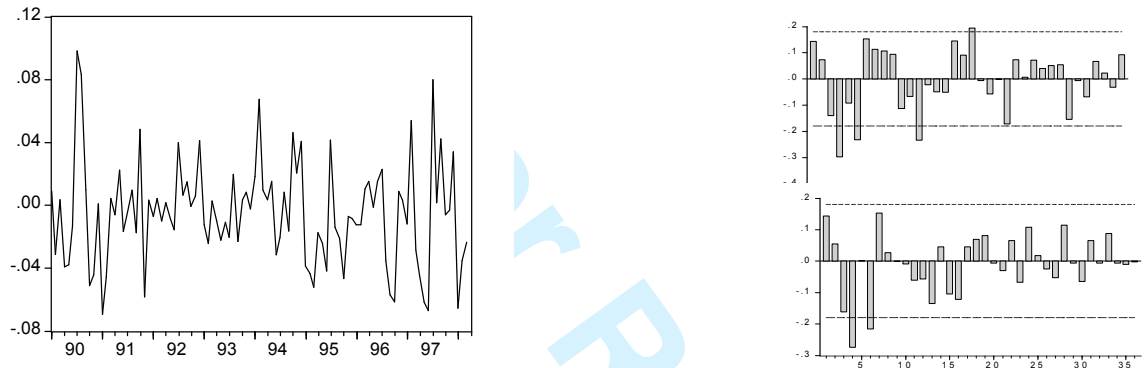


\section{Appendix 3: ObsExRa and ThtExRa}

Figure 6

Obs DEM / USD (Left) \& Tht DEM / USD (Right)
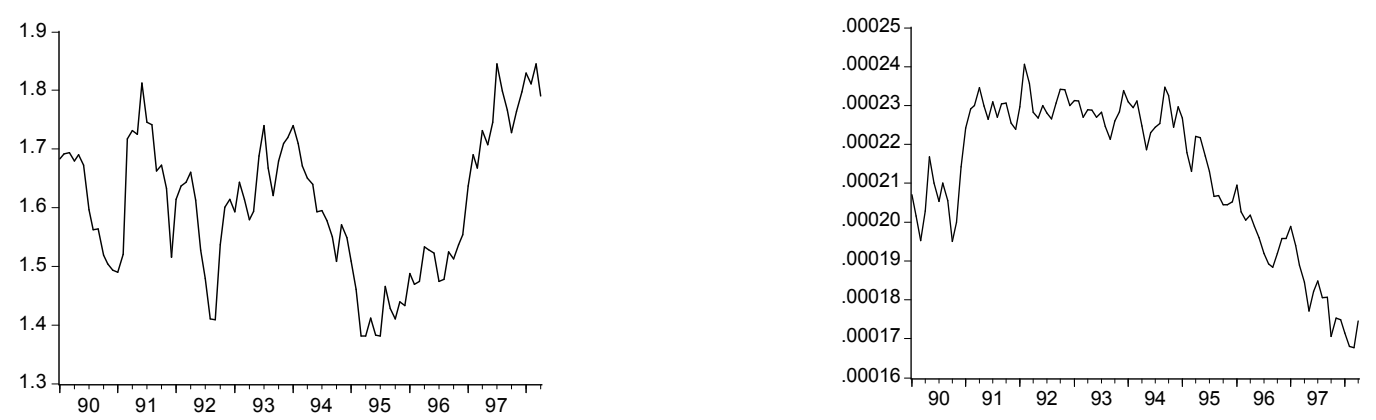

Figure 7

Obs GBP / USD (Left) \& Tht GBP / USD (Right)
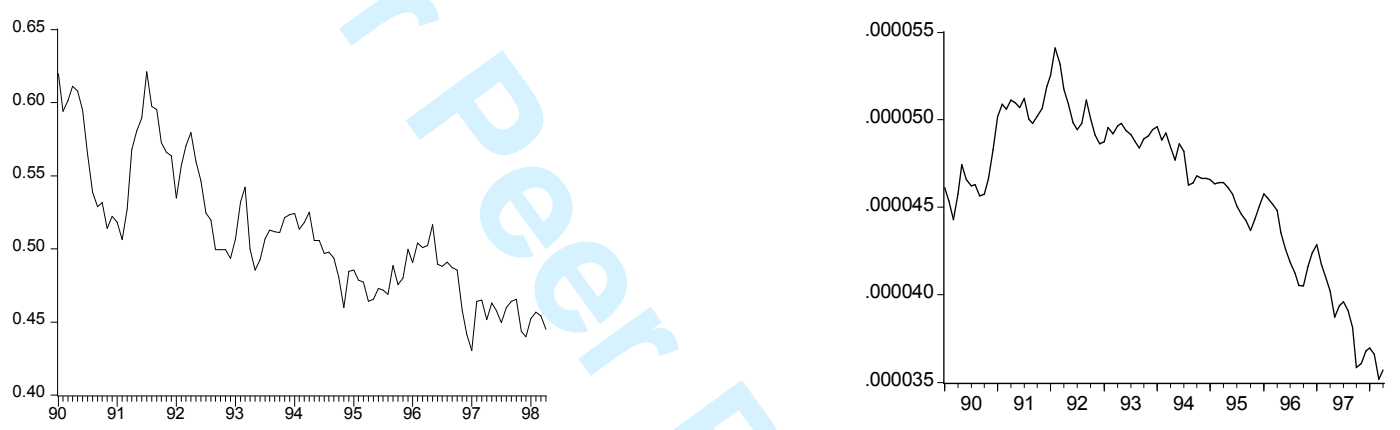

Figure 8

Obs ESP / USD (Left) \& Tht ESP / USD (Right)
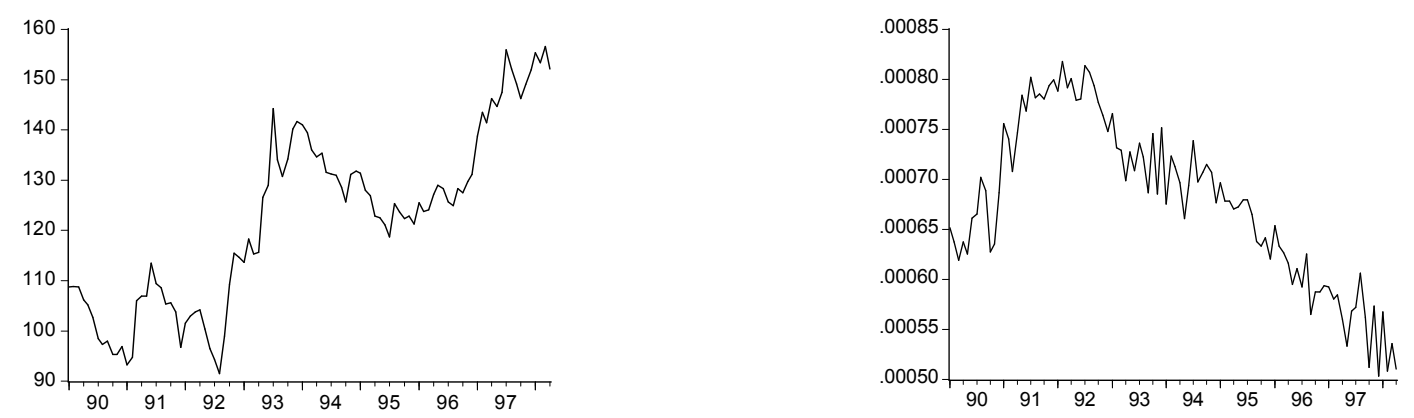
Figure 9

Obs JPY / USD (Left) \& Tht JPY / USD (Right)
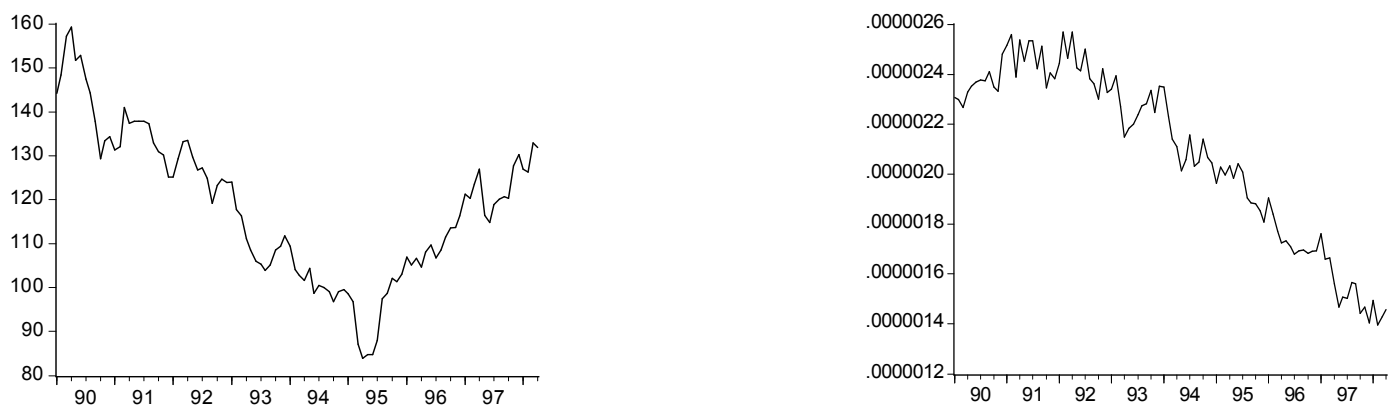

Figure 10

Obs GBP / DEM (Left) \& Tht GBP/ DEM (Right)
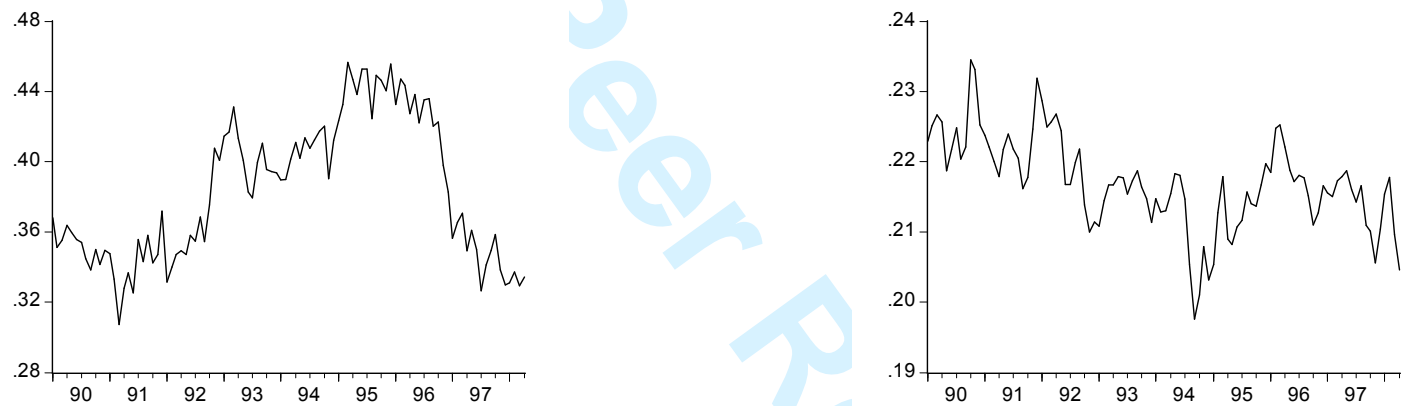

Figure 11

Obs ESP / DEM (Left) \& Tht ESP / DEM (Right)
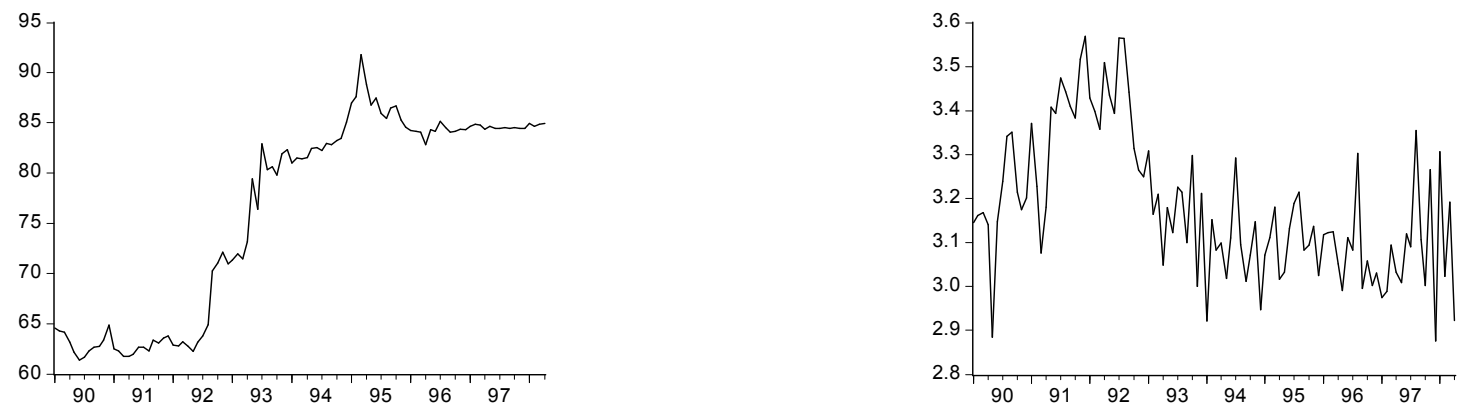


\section{Figure 12}

Obs JPY / DEM (Left) \& Tht JPY / DEM (Right)
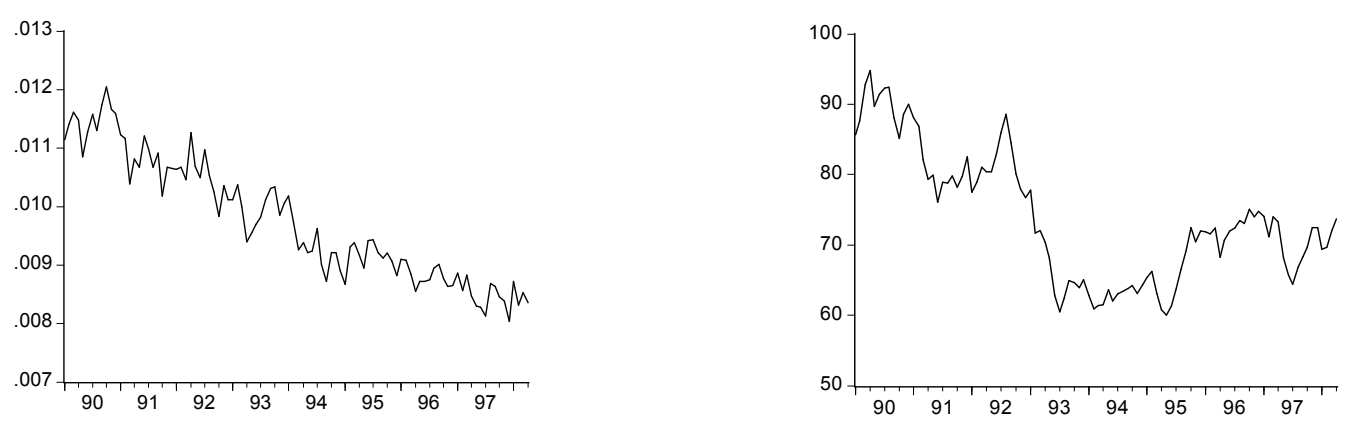